\title{
Multiprotein transcription factor UAF interacts with the upstream element of the yeast RNA polymerase I promoter and forms a stable preinitiation complex
}

\author{
Daniel A. Keys, ${ }^{1}$ Bum-Soo Lee, ${ }^{1}$ Jonathan A. Dodd, Toai T. Nguyen ${ }^{2}$ Loan Vu, Emmanuelle \\ Fantino, ${ }^{3}$ Laura M. Burson, Yasuhisa Nogi, ${ }^{4}$ and Masayasu Nomura ${ }^{5}$
}

Department of Biological Chemistry, University of California-Irvine, Irvine, CA 92717

Like most eukaryotic rDNA promoters, the promoter for rDNA in Saccharomyces cerevisiae consists of two elements: a core element, which is essential, and an upstream element, which is not essential but is required for a high level of transcription. We have demonstrated that stimulation of transcription by the upstream element is mediated by a multiprotein transcription factor, UAF (upstream activation factor), which contains three proteins encoded by $R R N 5$, RRN9, and $R R N 10$ genes, respectively, and probably two additional uncharacterized proteins. The three genes were originally defined by mutants that show specific reduction in the transcription of rDNA. These genes were cloned and characterized. Epitope tagging of RRN5 (or RRN9), combined with immunoaffinity purification was used to purify UAF, which complemented all three $(r r n 5, r r n 9$, and $r r n 10)$ mutant extracts. Using rrn10 mutant extracts, a large stimulation by UAF was demonstrated for a template containing both the core element and the upstream element but not for a template lacking the upstream element. In the absence of UAF, the mutant extracts showed the same weak transcriptional activity regardless of the presence or absence of the upstream element. We have also demonstrated that UAF alone makes a stable complex with the rDNA template, committing that template to transcription. Conversely, no such template commitment was observed with rrn10 extracts without UAF. By using a series of deletion templates, we have found that the region necessary for the stable binding of UAF corresponds roughly to the upstream element defined previously based on its ability to stimulate rDNA transcription. Differences between the yeast UAF and the previously studied metazoan UBF are discussed.

[Key Words: Saccharomyces cerevisiae; RRN5 gene; RRN9 gene; RRN10 gene; UAF; UBF]

Received January 24, 1996; revised version accepted February 27, 1996.

Studies on rRNA gene ( $r D N A)$ promoters in various eukaryotic systems, extending from human to yeast (Saccharomyces cerevisiae), have shown that despite extensive sequence diversification of the promoter regions, there is a common feature in their structural organization; the rDNA promoter consists of two elements: a core element and an upstream element (for review, see Sollner-Webb and Tower 1986; Reeder 1992; Paule 1994; Moss and Stefanovsky 1995). The core element covers $\sim 50$ nucleotides including the transcription start site and is essential (and sufficient) for specific transcription initiation. The upstream element, which is a region extending to about -150 with respect to the transcription start site, was originally identified by deletion analysis or substitution mutagenesis of promoters and is not absolutely required for specific initiation, but is required for a high level of transcription from the promoter. For example, for the human rDNA promoter, the upstream element /called upstream control element or UCE in this

\footnotetext{
${ }^{1}$ These authors contributed equally to this work.

Present addresses: ${ }^{2}$ VA Medical Center 151, Long Beach, California 90822 USA; ${ }^{3}$ Department of Physiology and Biophysics, University of California-Irvine, Irvine, California 92717 USA; ${ }^{4}$ Department of Biochemistry, Saitama Medical School, Moroyama, Iruma-gun, Saitama 350-04 Japan.

${ }^{5}$ Corresponding author.
}

system) is mapped from -156 to -107 , and the core element from -45 to +18 (Haltiner et al. 1986; see also Jones et al. 1988); and for the yeast rDNA promoter, the upstream element (domain II plus III; see Discussion) is from about -146 to about -51 , and the core element is from about -28 to about +8 (Musters et al. 1989; Kulkens et al. 1991; see also Choe et al. 19921. [For other systems studied, such as mouse, rat, and Xenopus, see Miller et al. (1985); Tower et al. (1986); Windle and Sollner-Webb (1986a,b); Henderson and Sollner-Webb (1990); Cassidy et al. (1987).] It has been suggested that the upstream element represents a site for the binding of transcription factors, which would stimulate assembly of a preinitiation complex. In some instances, including the yeast system, it has been shown that maintenance of correct spacing between these two elements is crucial in achieving a high level of transcription, suggesting that protein factors binding to the core and the upstream elements must be located at precise positions relative to each other (Windle and Sollner-Webb 1986b; Pape et al. 1990; Choe et al. 1992; Xie and Rothblum 1992).

Two transcription factors have been identified and well characterized for RNA polymerase I (Pol I) transcription in metazoan systems, UBF (upstream binding factor; Learned et al. 1986) and SL1 [promoter selectivity factor (Learned et al. 1986); also called by other names, 
e.g., TIF-IB (Schnapp and Grummt 1991)]. SL1 consists of TBP (TATA-binding protein) and three other polypeptides [TBP-associated factors (TAFs)], and is essential for in vitro transcription (Comai et al. 1992; Eberhard et al. 1993; Comai et al. 1994). In contrast to SLl, UBF, a dimer of a polypeptide containing several high mobility group (HMG) box domains (Jantzen et al. 1990; Bachvarov and Moss 1991; O'Mahoney and Rothblum 1991; McStay et al. 1991), is probably not absolutely required for Pol I transcription (e.g., see Smith et al. 1993). UBF was originally isolated as a protein that binds to the upstream element and was demonstrated to help recruit SLl to the template (Learned et al. 1986; Bell et al. 1988; Jantzen et al. 1990, 1992). However, UBF was also found to interact with the core element (Bell et al. 1988; Read et al. 1992). An interaction even with a downstream region consisting of an entirely transcribed region was also observed in the Xenopus system (Leblanc et al. 1993). It was suggested that such interactions are functionally important (Bell et al. 1988; Leblanc et al. 1993; BazettJones et al. 1994). In addition, mutations in the upstream element that abolish its ability to stimulate transcription did not affect the binding of UBF to the upstream element, as judged by a footprint analysis, leading to the suggestion that those mutations must affect the interaction of this element with protein factors other than UBF in this Xenopus system (Read et al. 1992; for similar cases in the human system, see Bell et al. 1988). Thus, despite convincing demonstrations of the stimulatory activities of the cis-acting element (upstream element) and of the trans-acting factor (UBF), the relationship between the two has remained unclear. Efforts to identify UBF homolog genes in lower eukaryotes including $S$. cerevisiae have so far been unsuccessful (unpublished work by several investigators cited in Yang et al. 1995).

Using a genetic system developed for S. cerevisiae, we have isolated many yeast mutants that are defective specifically in rDNA transcription by Pol I (Nogi et al. 1991; M. Nomura et al. unpubl.). By studying RRN6 and RRN7, we have demonstrated previously that these genes encode the 102 - and $60-\mathrm{kD}$ subunits of a complex $(\operatorname{Rrn} 6 / 7 \mathrm{com}$ plex) that also contains another protein with a molecular mass of $\sim 66 \mathrm{kD}$ (Keys et al. 1994). The Rrn6/7 complex was shown to be essential for rDNA transcription by Pol I in vitro and to participate in the formation of a preinitiation complex, although its stable binding to the promoter depends on the initial binding of some other factors. It was argued that this Rrn6/7 complex resembles SL1 rather than UBF, even though the purified complex does not contain TBP and there are no obvious sequence similarities between Rrn6p or Rrn $7 p$ and any of the three TAFs of human SL1 (Comai et al. 1994; Keys et al. 1994). In this paper we first describe experiments to characterize the $R R N 5, R R N 9$, and $R R N 10$ genes that have led to the discovery that proteins encoded by these genes are subunits of another multiprotein complex that functions as a Pol I-specific transcription factor. In contrast to the Rrn6/7 complex, this transcription factor is not absolutely required for rDNA transcription in vitro but is greatly stimulatory. We show that the complex containing Rrn5p, Rrn9p, and Rrn10p binds specifically to the upstream element of the yeast rDNA promoter, committing the template to transcription. We then discuss similarities and differences between UBF in metazoan systems and the newly identified yeast transcription factor complex, which we call UAF (for upstream activation factor).

\section{Results}

Mutation rm10-1 causes a preferential defect in $r R N A$ synthesis and defines gene RRN10

Like rrn5 and $r r n 9$ mutants described previously (Nogi et al. 1991), a mutant carrying rrn10-1 (NOY696) was originally isolated from NOY418, which carries the pGAL7$35 \mathrm{~S}$ rDNA fusion on a plasmid (pNOY103), as a mutant that grows on a galactose plate, but grows only very poorly on glucose. This mutation represents a complementation group that defines the RRN10 gene. As was done for other rrn mutants, including the rrn5 and $r m 9$ mutants to be discussed in this paper, rRNA synthesis in this rrn10 mutant was first analyzed in vivo in the presence of glucose, which represses the transcription of the pGAL7-35S rDNA fusion gene by Pol II, and was compared with rRNA synthesis in the absence of glucose, and with rRNA synthesis in the control RRN10 strain. As can be seen in Figure 1, synthesis of large rRNAs \{18S, $25 \mathrm{~S}$, and 5.8S rRNAs and other precursor rRNAs) in the mutant was strongly inhibited by glucose, relative to synthesis of $5 \mathrm{~S}$ and tRNAs (lanes 5,6; see legend to Fig. 1). No such inhibition was observed for the control parent strain (lanes 3,4$)$. We conclude that the rrn10 mutation causes a specific defect in Pol I-mediated rDNA transcription, and rRNA synthesis in the mutant growing in galactose medium is largely achieved by transcription of the $\mathrm{p} G A L 7-35 \mathrm{~S}$ rDNA fusion gene by Pol II. (Fig. 1 also includes the results obtained with the rrn 10A::LEU2 deletion mutant as well as $\operatorname{rrn} 5 \Delta:: L E U 2$, rrn9A::HIS3, and $r m 7 \Delta:: L E U 2$ mutant strains to be discussed below.)

\section{Cloning and characterization of the} RRN5, RRN9, and RRN10 genes

Cloning of RRN5, RRN9, and RRN10 genes was done using strain NOY697 carrying rrn5-1, strain NOY698 carrying rrn9-1, and strain NOY696 carrying rrn10-1, respectively, as was done for cloning of other $R R N$ genes (Nogi et al. 1993; Keys et al. 1994). Transformants with the growth characteristics of the wild type were isolated on glucose plates, the plasmids were recovered, and the genes were subcloned and sequenced. Physical structures of the chromosomal DNA regions containing RRN5, RRN9, and RRN10 are shown in Figure 2, a, c, and $\mathrm{e}$, and amino acid sequences of encoded proteins Rrn5p, Rrn9p, and Rrn10p, as deduced from nucleotide sequences, are shown in Figure 3.

RRN5 encodes a protein of 363 amino acids with a calculated molecular weight of 41,776 and a calculated 

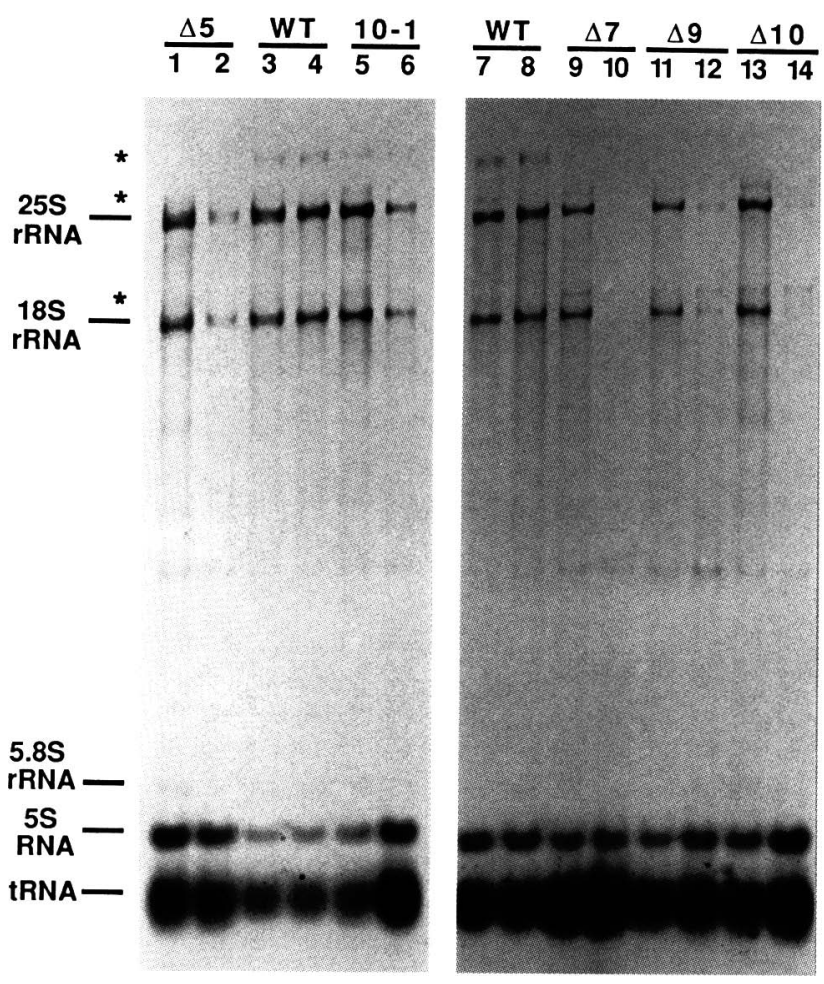

Figure 1. Polyacrylamide/agarose gel electrophoresis of RNA synthesized in various $r r n$ mutants and the parent strain growing in galactose medium (odd-numbered lanes) and after shifting to glucose medium (even-numbered lanes). Strains NOY418

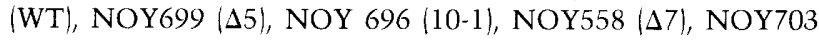
$\langle\Delta 9|$, and NOY704 $(\Delta 10)$ were grown at $30^{\circ} \mathrm{C}$ and ${ }^{3} \mathrm{H} \mid$ uridine pulse-labeling was carried out as described in Materials and methods. RNA samples containing approximately equal radioactivity were subjected to electrophoresis. Autoradiographs of gels are shown. Results from two independent experiments appear in lanes 1-6, and lanes 7-14, respectively. The positions of $25 \mathrm{~S}, 18 \mathrm{~S}$, and 5.8S rRNAs, as well as 5S and tRNAs are indicated. Positions of three precursor rRNAs, which presumably correspond to $35 \mathrm{~S}, 27 \mathrm{~S}$, and $20 \mathrm{~S}$ rRNAs, respectively, are indicated by asterisks. In these experiments, radioactive large $r R$ NAs relative to radioactive $5 S$ plus tRNAs were quantified without correction for background radioactivity. These values obtained for mutants in glucose medium divided by the corresponding values for the wild type were $0.17(\Delta 5), 0.13(10-1)$, $0.022(\Delta 7), 0.11(\Delta 9)$, and $0.071(\Delta 10)$.

isoelectric point of 6.99 . The protein is hydrophilic and contains a highly acidic region near the carboxyl terminus of the molecule (position $311-346 ; 44 \%$ acidic amino acids). The DNA sequence analysis revealed that the RRN5 gene is located on chromosome XII adjacent to a known gene, PUT1, which encodes the mitochondrial proline oxidase (Wang and Brandiss 1987) (Fig. 2a).

RRN9 encodes a protein of 365 amino acids with a calculated molecular weight of 42,786 , which is slightly larger than that of Rrn5p. The calculated isoelectric point of Rrn9p is 5.11 , and the protein is highly hydrophilic. From the DNA sequence upstream of $R R N 9$, we found that RRN9 is located downstream of a known gene, URA10, which encodes one of the two known orotate phosphoribosyl transferase isozymes (de Montigny et al. 1990) (Fig. 2c).

The protein (Rrn10p) encoded by RRN10 is 145 amino acids in size, its calculated molecular weight is 16,494 , and the isoelectric point is 4.95. After we completed the sequencing of this gene, the DNA sequence containing this region was published as part of the yeast genome sequencing project (Van Dyck et al. 1994), enabling us to conclude that RRN10 is on the left arm of chromosome II. RRN10 corresponds to an open reading frame called YBL0426 in this region.

We carried out standard gene disruption experiments to confirm the expected essential requirement of the

(a)

(b)
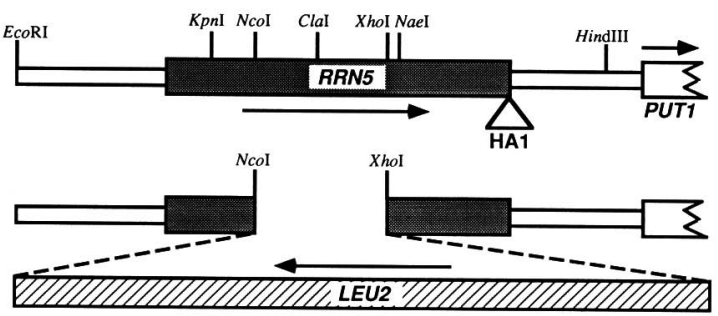

(c)

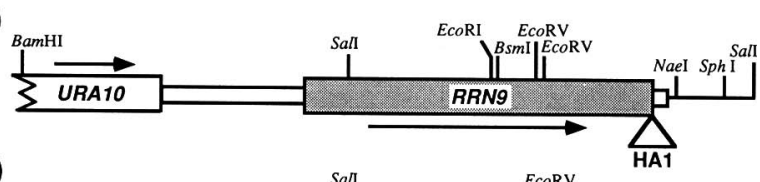

(d)

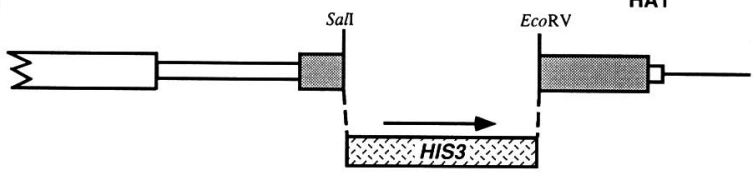

(e)

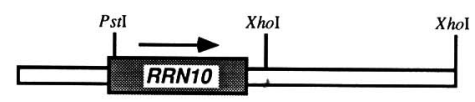

(f)

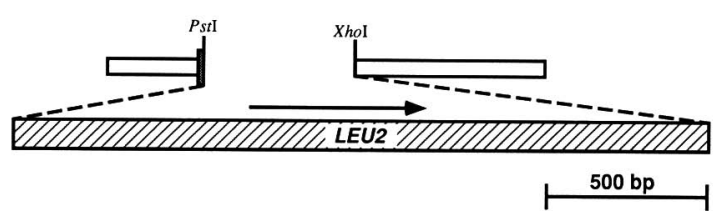

Figure 2. Restriction enzyme maps of the $R R N 5, R R N 9$, and $R R N 10$ genomic regions. $(a)$ The $R R N 5$ region; $\{b \mid$ insertion of a 2.2-kb LEU2 fragment between the NcoI and XhoI sites to construct the $\operatorname{rrn} 5 \Delta:: L E U 2$ null allele; (c) the RRN9 region; (d) insertion of a 0.6-kb HIS3 fragment between the SalI and EcoRV sites to construct the rrn9A::HIS3 null allele; $(e)$ the RRN10 region; $(f)$ insertion of a $2.2-\mathrm{kb} L E U 2$ fragment between the PstI and XhoI sites to construct the $\operatorname{rrn} 10 \Delta::$ LEU2 null allele. Protein-coding regions of $R R N 5, R R N 9$, and $R R N 10$ are stippled. The LEU2 fragment is hatched; the HIS3 fragment is crosshatched. The $5^{\prime}$ region of $P U T 1$, located downstream of RRN5, and the $3^{\prime}$ region of URA10, located upstream of $R R N 9$, are shown by open boxes. The positions of DNA inserts encoding the triple-HAl-epitope are shown by open triangles. Arrows show the direction of transcription. Vector sequences located downstream of RRN9 in the original library isolate (pNOY187) are shown by a solid line in $c$ and $d$. 
Keys et al.

(a)

Rrn5p

1 MEHCQLRKYV ELYNKEVEEF YNGARSGRPA EFHPSKVHVK SIHEKAGTAN AGVEISSVGV DWDSEEKNTE FWCLSRYSIH 81 RVDEWRSLIP RKSAMEILGY YRLLRRASAS ARSRKAGDDG APIAYEMSAE WVALETKLSE TVMAITEGAA EVADEEGHCE 1 GLIDYESWKR RWVAIYSHSR IAEIRPLPRH ALPLSRRPTQ TLERCVSRYT RTLLWCTALA GMASRSVSAR AAESRGHKSL 241 PTVVTRRQVE RALCTEARSG DLHVLPRRIV LTLRKWELDY PREGKLFRTK EMAHLFLQSQ LSRRDAPPVH QDENQENQEN 321 QENQEQDNTA SEGESEAERD EIDEADLFRS ALHENQLLKW LSK

(b)

\section{$\operatorname{Rrn9p}$}

1 MSDLDEESQI ETQIDAPIED IIRGSELTTT TADKETLKSA NELLDSLEHS HRVDLSLHLY SAYLIKRLLY KANEKKHFYE 8: VNQEVKTQIK DNWTSWPNPN TIIDPSVDKL YEDIPEGIAN VSVQPGEISN RALMHASDMM RVELDAQWQK ELSKSALDHD 161 VTLDVDELNI PNEISRNILV KLDSLFEGLH DKIAKENEFD VRQDKHSNNI RANQIDDEPM QANRRIKYTY HDLVSRGCEM 241 NEDMTDIYMK SLELYNDIPE KYKKRKERLP KQILKKYHQP KKTSSYLKEL LSKTREDEIP VEKLLKDKRL TSKDKSKLQR 32 INREETEDAL NKRTEFQVKG YLEDENEISD YELDDCLIEL PNGNI

Figure 3. Predicted amino acid sequences of Rrn5p, Rrn9p, and Rrn10p. The nucleotide sequences of RRN5, RRN9, and $R R N 10$ have been submitted to the GenBank data base, under accession numbers U43680, U43681, and U43682, respectively.

\section{(c)}

\section{Rrn10p}

1 MDRNUYEACS NIIKEFGTHV VSADEVLAEK IDNAVPIPEK TREEIDADVE KDRNEGVFEG NIIPDIDLRV VHYYATQLCL 81 NKYPHLINAF DETSLITLGL LIEKWVKDYL TSIQTEQGRQ SKVIGKGPCE FISKHIDYRH APGNI

three cloned genes for growth and to construct strains that would be useful for purification of proteins encoded by the genes. DNA fragments carrying disrupted genes described in Figure 2, b, d, and $\mathrm{f}, \operatorname{rrn} 5 \Delta:: L E U 2$, rrn $9 \Delta:: H I S 3$, or $\operatorname{rrn} 10 \Delta:: L E U 2$, were used to construct diploid strains that carry one chromosome with the wild-type $R R N$ allele and another chromosome with one of the corresponding genes replaced by the disrupted allele (NOY679, NOY678, and NOY677, respectively; Table 1). These diploid strains were sporulated, tetrads were dissected on YEP-glucose medium, and their segregation patterns were monitored at $25^{\circ} \mathrm{C}$ or $30^{\circ} \mathrm{C}$. To our initial surprise, we found that these genes were not absolutely required for spore germination or cell growth. As can be seen in Figure 4, a-c, tetrads from three diploid

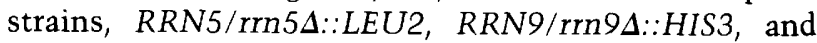
$R R N 10 /$ rrn 10 $:: L E U 2$, all gave a $2: 2$ segregation pattern with two large colonies and two for occasionally one or zero) very small colonies. The very small colonies carried the LEU2 or HIS3 genes used for disruption and represent haploid deletion segregants. In contrast, paral-

(a)
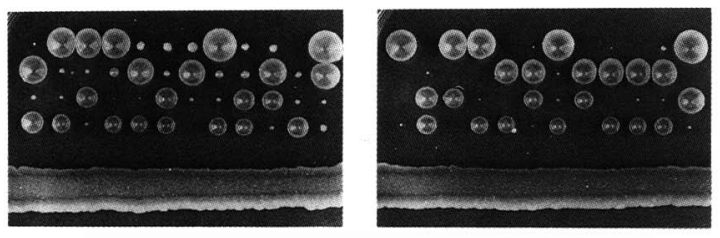

(c)
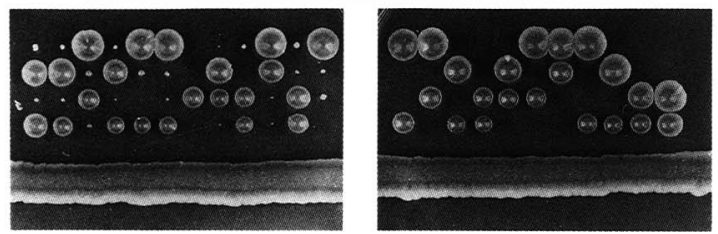

(d)

Figure 4. Tetrad analysis of diploid strains, NOY679 (RRN5/ rrn5A::LEU2) (a), NOY678 (RRN9/rrn9A::HIS3) (b), NOY677 (RRN10/rrn10A::LEU2) (c), and NOY548 (RRN7/rrn7A::LEU2) (d). Diploid cells were sporulated, tetrad spores were dissected, and haploid segregants were grown on YEP-glucose plates for 10 days at $30^{\circ} \mathrm{C}$. lel tetrad dissection of a diploid strain, RRN7/ rrn $7 \Delta:: L E U 2$ (NOY548), showed the segregation pattern of two viable and two nonviable spores (Fig. 4d), as reported previously (Keys et al. 1994). Thus, it appears that in contrast to $R R N 6$ and $R R N 7$, none of the three genes studied here, RRN5, RRN9, and RRN10, is absolutely essential. It should be noted that the original mutant strains, including those used for gene cloning, were able to grow very slowly on glucose media, but their growth was sufficiently weak so that the strains could be used to clone the genes by complementation.

Using the diploid strains carrying the disrupted rrn5 (or rrn9 or rrn10) described above, we have constructed haploid strains with the chromosomal RRN5 (or RRN9 or RRN10) disrupted and carrying the $\mathrm{p} G A L 7-35 \mathrm{~S}$ rDNA fusion on the pNOY103 plasmid (NOY699, NOY703, and NOY704; see Fig. 2 and Table 1). These strains can grow on galactose but very poorly on glucose. Some of these strains were used to make extracts described below. In addition, strains with the chromosomal $R R N 5$ (or $R R N 9$ ) disrupted and carrying a triple-HA1-tagged RRN5 (or $R R N 9$ 9) gene on a centromeric plasmid were also constructed (NOY662 and NOY674) and utilized to detect and affinity purify Rrn5p (or Rrn9p) with monoclonal antibodies against the HAl epitope, as described below.

Complementation of rrn5, rrn9, and rrn10 mutant extracts in vitro and purification of a multiprotein complex containing Rrn5p, Rrn9p, and Rrn10p

Preliminary experiments showed that extracts (PC-300 plus D-300 fractions; see Materials and methods) prepared from rrn5, rrn9, or rrn10 mutants showed very weak activities in transcription of rDNA templates, relative to extracts from the wild-type strain /data not shown; for the rrn10 extract, see Fig. 8, lane 1, discussed below). Therefore, we attempted to purify $\operatorname{Rrn} 5 p, \operatorname{Rrn} 9 p$, and Rrn 10p, or protein complexes containing these proteins to see whether they complement respective mutant extracts.

We started with extracts from NOY674, which expresses triple-HA1-tagged $\operatorname{Rrn} 9 \mathrm{p}\left[(\mathrm{HA} 1)_{3}-\mathrm{Rrn} 9 \mathrm{p}\right]$, and ex- 
Table 1. Yeast strains and plasmids used

\begin{tabular}{|c|c|}
\hline Strain or plasmid & Description \\
\hline \multicolumn{2}{|l|}{ Strain } \\
\hline NOY397 & $\begin{array}{l}\text { MATa/MAT ade2-1/ade2-1 ura3-1/ura3-1 his3-11/his3-11 trp1-1/trp1-1 leu2-3,112/leu2-3,112 } \\
\text { can1-100/can1-100 }\end{array}$ \\
\hline NOY418 & MATa ade2 ade3 leu2 ura3 lys2 can1 pNOY103 (Nogi et al. 1991) \\
\hline NOY423 & $\begin{array}{l}\text { MATa ade2 ade3 leu2 ura3 trp1 can1 [a meiotic segregant of the cross between strains CH1305 (Kranz } \\
\text { and Holm 1990) and NOY396 (Nogi et al. 1991)] }\end{array}$ \\
\hline NOY424 & NOY423 carrying pNOY 103 \\
\hline MOY610 & MATa/MATa ade2/ade2 ade3/ade3 leu2/leu2 ura3/ura3 trp1/trp1 can1/can1 \\
\hline NOY697 & MATa ade2 ade3 leu2 ura3 lys2 can1 rrn5-1 pNOY103 \\
\hline NOY705 & MATa ade2 ade3 leu2 ura3 lys2 can1 rm5-2 pNOY103 \\
\hline NOY 698 & MAT $\alpha$ ade2 ade 3 leu2 ura3 trp1 his can1 rrn9-1 pNOY103 \\
\hline NOY696 & MAT $\alpha$ ade2 ade3 leu2 ura3 lys2 his can1 rrn10-1 pNOY103 \\
\hline NOY679 & $\begin{array}{l}\text { MATa/MAT } \alpha \text { ade2-1/ade2-1 ura3-1/ura3-1 his3-11/his3-11 trp1-1/trp1-1 leu2-3,112/leu2-3,112 } \\
\text { can1-100/can1-100 RRN5/rrn5A::LEU2 }\end{array}$ \\
\hline NOY548 & $\begin{array}{l}\text { MATa/MAT ade2-1/ade2-1 ura3-1/ura3-1 his3-11/his3-11 trp1-1/trp1-1 leu2-3,112/leu2-3,112 } \\
\text { can1-100/can1-100 RRN7/rrn7A::LEU2 (Keys et al. 1994) }\end{array}$ \\
\hline NOY 678 & $\begin{array}{l}\text { MATa/MATa ade2-1/ade2-1 ura3-1/ura3-1 his3-11/his3-11 trp1-1/trp1-1 leu2-3,112/leu2-3,112 } \\
\text { can1-100/can1-100 RRN9/rrn9A::HIS3 }\end{array}$ \\
\hline NOY677 & 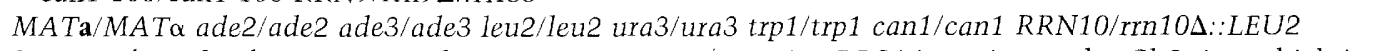 \\
\hline NOY577 & $\begin{array}{l}\text { MAT } \alpha \text { ade } 2 \text { ade } 3 \text { leu2 ura } 3 \text { trp } 1 \text { his can } 1 \text { rm } 5:: T R P 1 \text { (contains TRP1 insertion at the ClaI site, which is } \\
\text { within the codon Ile } 161 \text { of } R R N 5 \text { ), pNOY103 }\end{array}$ \\
\hline NOY 662 & NOY577 carrying pNOY330 instead of pNOY103 \\
\hline NOY 699 & 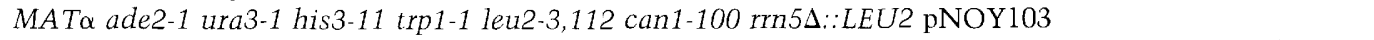 \\
\hline NOY558 & MATa ade2-1 ura3-1 leu2-3,112 trp1-1 his3-11 can1-100 rrn7A::LEU2 pNOY103 (Keys et al. 1994) \\
\hline NOY703 & MATa ade2-1 ura3-1 his3-11 trp1-1 leu2-3,112 can1-100 rrn9A::HIS3 pNOY103 \\
\hline NOY674 & NOY703 carrying pNOY332 instead of pNOY103 \\
\hline NOY 690 & MAT $\alpha$ ade2 ade3 leu2 ura3 trp1 can1 rrn10D::LEU2 \\
\hline NOY704 & MATa ade 2 ade3 leu2 ura3 trp1 can1 rrn10A::LEU2 pNOY103 \\
\hline \multicolumn{2}{|r|}{ (1) } \\
\hline pRS315 & yeast-E. coli shuttle vector (Skiorski and Hieter 1989); LEU2, CEN6, ARSH4 \\
\hline GTEP1 & $\begin{array}{l}\text { derivative of pBluescript IISK }- \text { - ) contains a NotI fragment that encodes three copies of the HAl epitope } \\
\text { sequence YPYDVPDYA (Roof et al. 1992) }\end{array}$ \\
\hline pSIRT & a derivative of pEMBL Ye30- $\Delta 6$ that carries the mini rDNA gene called SIRT (Musters et al. 1989) \\
\hline pNOY103 & high-copy-number plasmid carrying GAL7-35S rDNA, $A D E 3,2 \mu$, amp (Nogi et al. 1991) \\
\hline pNOY 230 & the original plasmid carrying RRN5 recovered from a YCpN1 (CEN3 ARS TRP1) bank \\
\hline pNOY187 & the original plasmid carrying $R R N 9$ on a $\sim 5-\mathrm{kb}$ DNA fragment, recovered from a YCpN1 bank \\
\hline pNOY337 & $\begin{array}{l}\text { the original plasmid carrying } R R N 10 \text { on a } \sim 3.6-\mathrm{kb} \text { DNA fragment recovered from a YEp } 213(L E U 2,2 \mu \text {, } \\
\text { amp bank }\end{array}$ \\
\hline pNOY328 & $\begin{array}{l}\text { derivative of pPC97 (LEU2, CEN6, amp; a gift from D. Nathans; similar to pPC62 described by Chevray } \\
\text { and Nathans 1992); the 1.6-kb XhoI-Xhol fragment carrying the ADC1 promoter was removed; retains } \\
\text { multicloning sites present upstream of the } A D C 1 \text { terminator }\end{array}$ \\
\hline pNOY330 & $\begin{array}{l}\text { carries } \sim 1.7-\mathrm{kb} \text { DNA fragment encoding triple-HAl-tagged Rrn5p inserted between Sall and SacI of } \\
\text { pNOY328 (sce text) }\end{array}$ \\
\hline pNOY335 & carries $-2.1-\mathrm{kb}$ Bam HI-NaeI fragment containing RRN9 inserted between BamHI and NaeI of pRS315 \\
\hline pNOY332 & carries $\sim 2.2-\mathrm{kb}$ DNA fragment encoding triple HAl-tagged Rrn9p between BamHI and NaeI of pRS315 \\
\hline pNOY3114 & 2.7-kb BgIII fragment carrying LEU2 (from YEp13) inserted into the BamHI site of pUC19 \\
\hline pNOY 3220 & $\begin{array}{l}\text { derivative of pBluescript KS }(+1 \text {; carries a NotI-SacI fragment encoding } 37 \text { amino acids, which contain } \\
\text { three copies of the HAl peptide sequence, inserted between the NotI and SacI sites }\end{array}$ \\
\hline pNOY3124 & $\mid=$ pATH23| TrpE fusion/expression vector (Koerner et al. 1991) \\
\hline
\end{tabular}

tracts from NOY662, which expresses triple-HAl-tagged Rrn5p [(HAl $)_{3}-$ Rrn5p], and used immunoaffinity purification as an initial purification step. By testing fractions after this step for the presence of proteins encoded by several $R R N$ genes using polyclonal antibodies in addition to testing $(\mathrm{HAl})_{3}-\mathrm{Rrn} 9 \mathrm{p}$ [or $(\mathrm{HAl})_{3}-\mathrm{Rrn} 5 \mathrm{p}$ ] using anti-HAl monoclonal antibody, it soon became clear that Rrn5p, Rrn9p, and Rrn10p copurify, and the preparations that were active in complementing rrn9 (or rrn5) extracts were also active in complementing rrn5 (or rrn9) and rrn 10 extracts. Figure 5 summarizes the purification scheme used for extracts containing $(\mathrm{HA} 1)_{3}-\mathrm{Rrn} 5 \mathrm{p}$ as well as for those containing $(\mathrm{HA} 1)_{3}-\mathrm{Rrn} 9 \mathrm{p}$.

The results of analysis of fractions obtained from the final Superose 12 gel filtration column are shown in Figure 6 for a purification starting from an extract containing (HA1) $)_{3}-$ Rrn5p. It can be seen that both Rrn9p and Rrn 10p copurified with $(\mathrm{HA} 1)_{3}-\mathrm{Rrn} 5 \mathrm{p}$ as assayed by 


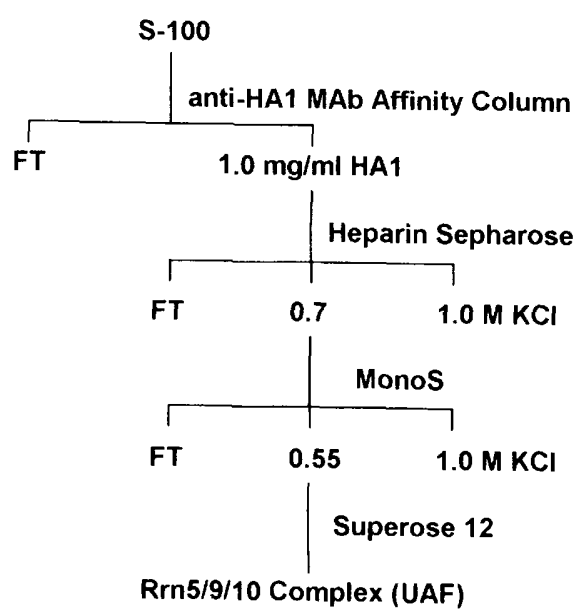

Figure 5. Scheme for purification of Rrn5/9/10 complex (UAF).

SDS-PAGE followed by immunoblot analysis of column fractions (Fig. 6b). The column fractions were also analyzed for proteins by SDS-PAGE followed by silver staining (Fig. 6a). Five bands were consistently observed in the fractions containing Rrn5p, Rrn9p, and Rrn10p (see legend to Fig. 6). The apparent molecular masses of these five proteins were $58,50,30,18$, and $17 \mathrm{kD}$, as estimated from positions of molecular mass markers; the $58-\mathrm{kD}$ component corresponded to $(\mathrm{HAl})_{3}-\mathrm{Rrn} 5 \mathrm{p}$ and the 50 $\mathrm{kD}$ component corresponded to Rrn9p for the preparation obtained from the $(\mathrm{HAl})_{3}-R R N 5$ strain, and the 17 $\mathrm{kD}$ component corresponded to Rrn10p, as judged by comparison with immunoblot analysis. The sum of the apparent molecular mass of these five proteins is $173 \mathrm{kD}$, and this is roughly consistent with the peak position of the active complex in this sizing column; the peak position was slightly behind the size marker $(\beta$-amylase $(206 \mathrm{kD})$ but several fractions ahead of another size marker, BSA (66 kD) (data not shown). Thus, Rrn5p, Rrn9p, and Rrn10p appear to be components of a multiprotein complex (Rrn5/9/10 complex). This complex appears to contain two additional proteins with sizes of $\sim 30 \mathrm{kD}(\mathrm{p} 30)$ and $\sim 18 \mathrm{kD}(\mathrm{p} 18)$, respectively (see legend to Fig. 6 for other protein bands seen in Fig. Ga). It should be noted that $\mathrm{p} 30$ is not TBP $(27 \mathrm{kD})$ and the purified preparation does not contain TBP, as analyzed by Western blot with polyclonal antibodies against yeast TBP (data not shown). Column fractions were also analyzed for their ability to complement rrn5, rrn9, and $r r n 10 \mathrm{mu}-$ tant extracts (Fig. 6c-e). The three complementation activities were coeluted from the column, and their peak fractions (Fig. 6, fractions 35-39) corresponded to the peak fractions revealed by protein gels. We conclude that a multiprotein complex containing Rrn5p, Rrn9p, and Rrn10p (and probably two additional proteins, p30 and p18) is the transcription factor missing in extracts prepared from $r m 5$, rrn9, or rrn10 mutants. [It should be noted that a close examination of the data shown in Fig. 6 suggests that the protein composition of the complex may not be homogeneous; notably the ratio of $\mathrm{p} 30$ to $\mathrm{p} 18$ changes from earlier fractions to later fractions. Thus, establishing p30 and p18 as genuine components of the Rrn5/9/10 complex must await cloning of their genes and appropriate genetic and biochemical analyses.]

We note that the molecular mass of $(\mathrm{HAl})_{3}-\mathrm{Rrn} 5 \mathrm{p}$ calculated from the amino acid sequence is $\sim 46 \mathrm{kD}[41.8$ $\mathrm{kD}$ for Rrn5p plus $4.3 \mathrm{kD}$ for the (HA1) ${ }_{3}$ epitope] and is considerably smaller than $58 \mathrm{kD}$ estimated from its mobility in SDS-PAGE. Similarly, the molecular mass of Rrn9p calculated from the amino acid sequence is $\sim 42.8$ $\mathrm{kD}$, which is smaller than $50 \mathrm{kD}$ estimated from the mobility in SDS-PAGE. We do not know the reason for these discrepancies.

To confirm the presence of Rrn5p, Rrn9p, and Rrn10p (and $\mathrm{p} 30$ and $\mathrm{p} 18$ ) in a single transcription factor complex, we repeated purification of the active complex starting from NOY 674 , which carries the $(\mathrm{HAl})_{3}-R R N 9$ gene, instead of the $(\mathrm{HAl})_{3}-R R N 5$ strain. The same purification method was used with an immunoaffinity purification as the first step. Fractions from the final Superose 12 gel filtration column were analyzed for protein components using SDS-PAGE followed by silver staining and Western immunoblot, and for in vitro complementation activities. The results confirmed the conclusion obtained with the preparations purified from the $(\mathrm{HA} 1)_{3}-$ RRN5 strain. Activities that could complement rrn5, rrn9, and rrn10 mutant extracts were copurified as a complex containing Rrn5p, $(\mathrm{HA} 1)_{3}-\mathrm{Rrn} 9 \mathrm{p}$, and Rrn10p. The presence of the two other proteins, $\mathrm{p} 30$ and $\mathrm{p} 18$, in the complex was also demonstrated (data not shown).

\section{The upstream element is required for stimulatory activity of UAF}

As described in the introductory section, Pol I promoters consist of two domains: the core element, which is essential, and the upstream element, which is not essential but stimulatory. As already noted above, extracts prepared from $\operatorname{rrn} 5$, rrn9, or rrn10 mutants showed great reduction in Pol I transcription activity; nevertheless, we observed weak but definite activity in these extracts. Therefore, we thought that the complex might be involved in the stimulation mediated by the upstream element of the Pol I promoter. Transcription experiments using rrn10 extracts were carried out in which two DNA templates were compared: one with the wild-type promoter (called pSIRT; see Fig. 7a), and the other with a mutant promoter carrying a deletion from -208 to -91 (i.e., deletion of a region abolishing most of the stimulation by the upstream element; see Musters et al. 1989; Kulkens et al. 1991; Fig. 7b). With the mutant promoter, no significant stimulation by the Rrn5/9/10 complex was observed (Fig. 8, cf. lane 4 and 2), whereas a large stimulation was observed with the wild-type promoter (Fig. 8, cf. lane 3 and 1; see the legend). In the absence of the complex, no significant difference was observed in transcription between the wild-type and the mutant promoter (Fig. 8, cf. lane 1 and 2; see the legend), indicating that stimulation by the upstream element is mediated by 
(a)

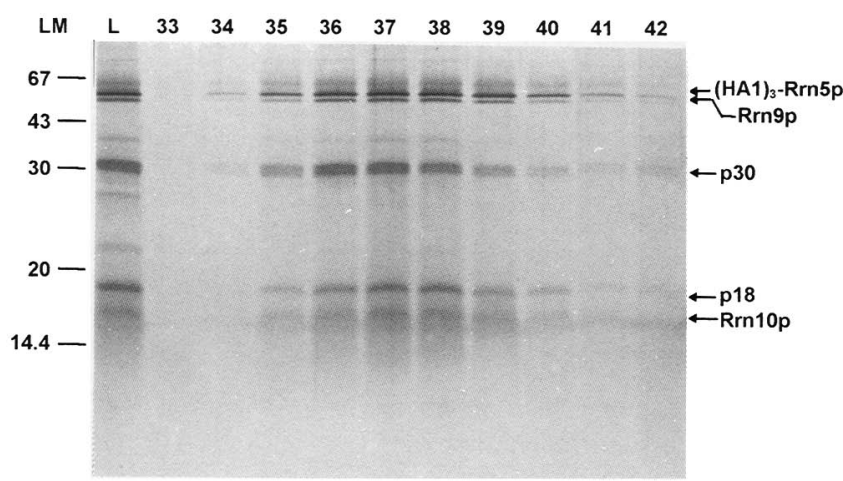

(b)

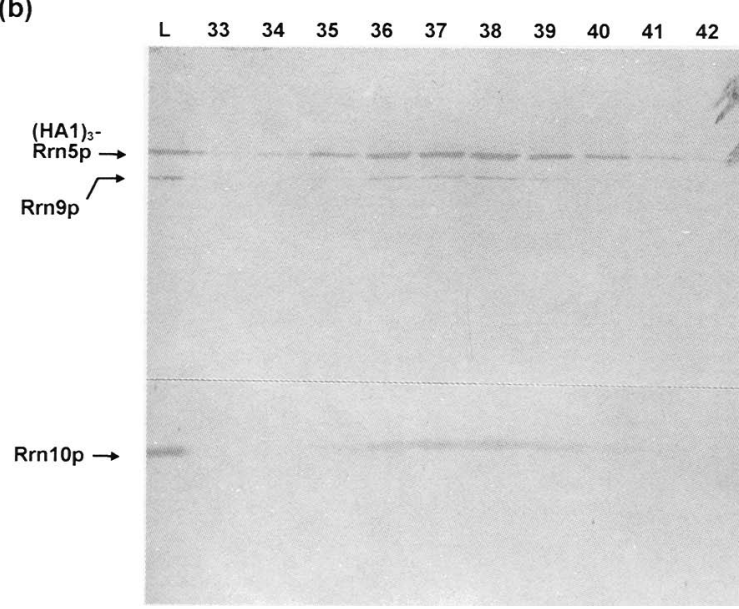

(c)

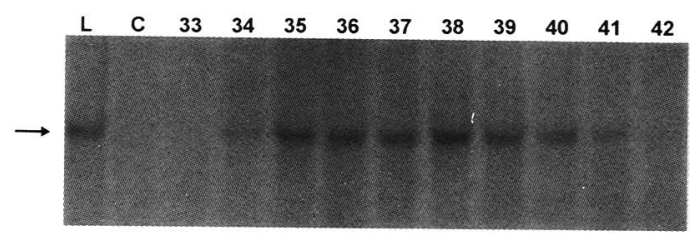

(d)

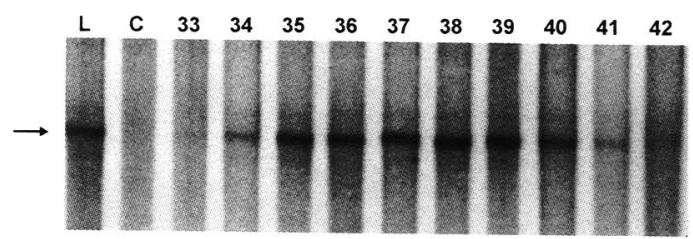

(e)

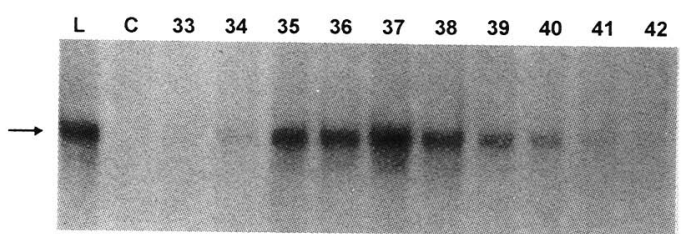

Figure 6. Purification of the Rrn5/9/10 complex (UAF) from NOY662 expressing $(\mathrm{HAl})_{3}-\mathrm{Rrn} 5 \mathrm{p}$. The complex was purified as diagramed in Fig. 5 and described in Materials and methods. (a) Individual fractions eluted from Superose 12 column analyzed by SDS-PAGE followed by silver staining of protein $[120 \mu \mathrm{l}$ of Superose fraction per lane; concentrated by Microcon 10 (Amicon); fractions $33-42$, as indicated]. Twenty microliters of the columnload fraction (Mono S peak fraction concentrated by ultrafiltration) was applied to lane L. The positions of molecular weight markers (LM) are as indicated. (b) Western blot analysis of Superose 12 fractions. Forty microliters of Superose fraction was applied per lane. After transferring onto a PVDF (Immobilon-P, Millipore) filter, the filter was cut in half. The top portion was first analyzed using anti-Rrn9p polyclonal antisera to detect Rrn9p. After washing, the same filter was subjected to analysis with anti-HAl monoclonal antibody to detect (HA1) - Rrn5p. The bottom half of the filter was analyzed using anti-Rrn 10p polyclonal antisera. Ten microliters of column-load fraction was applied to lane L. (SDS-PAGE for $a$ did not contain dithiothreitol; SDS-PAGE for $b$ contained it and was run for a longer time than that for a.) $(c-e)$ Activities of the Superose 12 fractions to complement rrn5, rrn9, and $\operatorname{rrn} 10$ mutant extracts were analyzed by in vitro transcription. Transcription was carried out with D-300 and PC-300 fractions prepared from rrn5 (NOY705) (c), rrn (NOY703) (d), and rrn10 (NOY696) (e) mutant strains, supplemented with $1.5 \mu$ l of the indicated Superose fraction or with $0.5 \mu l$ of column-load fraction (lane L). In lane C, control reactions were carried out using mutant D-300 and PC-300 fractions with no other addition. We note that the SDS-PAGE gel stained with silver showed a clear band just below the Rrn9p band $(a)$. In other experiments with different preparations, such a band was not seen. It is not known whether this band represents a genuine component distinct from Rrn9p. Similarly, the p30 band appears as a doublet in this gel, but this was not seen in other experiments. We also note that there are other faint bands (e.g., one at $\sim 80-\mathrm{kD}$ position and another at $\sim 39-\mathrm{kD}$ position) in the peak fractions showing stimulatory activity. The significance of these bands is not known.

this transcription factor complex. For this reason, we call the Rrn5/9/10 complex UAF.

\section{UAF is necessary and sufficient for template commitment}

It was demonstrated previously that when an rDNA template was incubated with extracts or crude transcription factor fractions in the absence of nucleoside triphosphates, a transcription factor(s) forms a stable complex with the template and fails to participate in the transcription of a subsequently added second template. This was shown for several Pol I transcription systems /Cize- wski and Sollner-Webb 1983; Wandelt and Grummt 1983; Kownin et al. 1985; Clos et al. 1986; Kato et al. 1986), including yeast systems using crude extracts (Kulkens et al. 1991), rrn6 mutant extracts supplemented with the Rrn6/7 complex (Keys et al. 1994), or partially purified chromatographic fractions (Riggs et al. 1995). We carried out similar template commitment experiments using rrn10 extracts supplemented with UAF and examined a possible role of UAF in the formation of stable preinitiation complex.

As shown in Figure 9, when rrn10 extracts supplemented with UAF were preincubated with a template DNA, the transcription of a subsequently added second 
Keys et al.

(a)

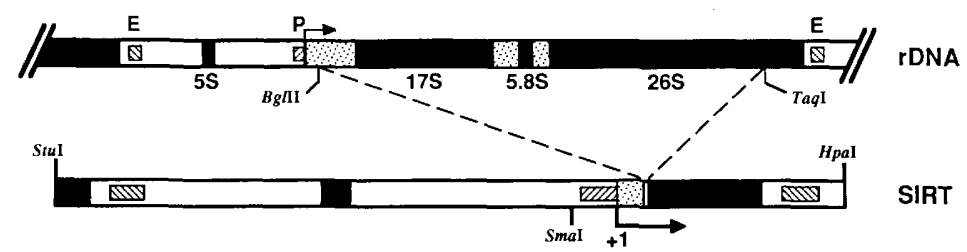

(b)

Figure 7. rDNA template, pSIRT, and deletion mutant templates. (a) The minigene SIRT (contained in plasmid pSIRT) aligned with a rDNA unit. Solid bars represent the coding regions of the rRNA genes. Transcribed and nontranscribed spacers are represented by stippled and open bars, respectively. Boxes, designated $\mathrm{P}$ and $\mathrm{E}$, are the Pol I promoter and the enhancer/terminator regions, respectively. $(b)$ The promoter region and various deletion constructs. The names of deletion constructs indicate the first and the last base pair deleted. Locations of the upstream element (UE) and the core element within the promoter are indicated.
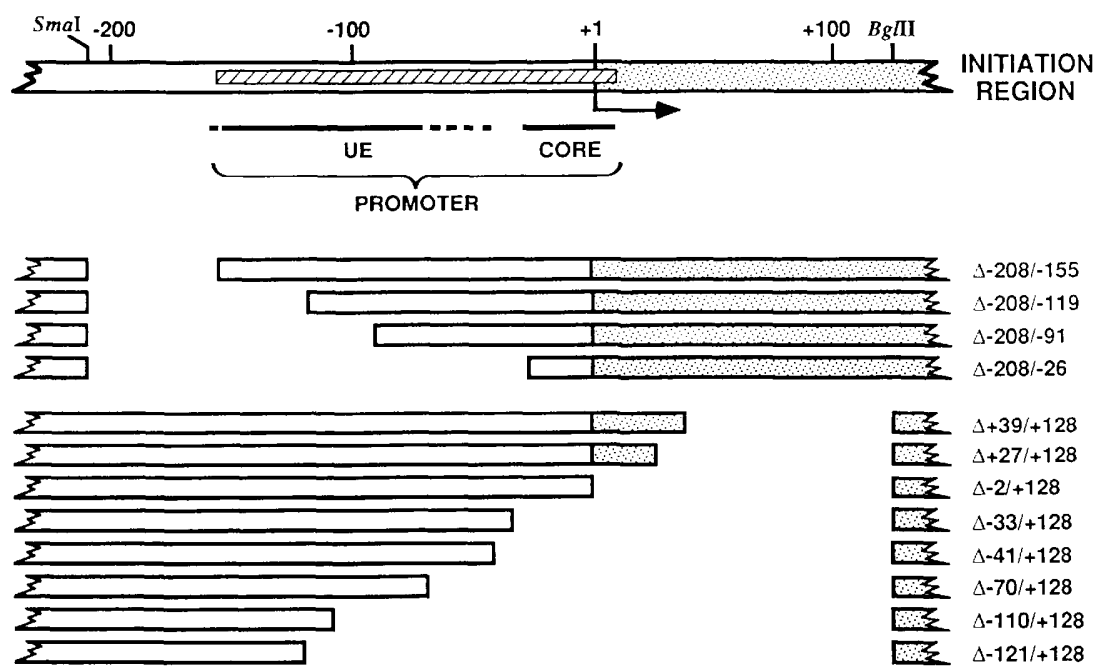

template was greatly reduced, as expected, indicating the formation of a stable complex of some transcription factors with the first template (lanes 2 and 3, cf. controls, lanes 1,4 , and 5). When UAF was omitted from the preincubation step and added immediately following the second template, both templates were transcribed (Fig. $9 \mathrm{a}$, lanes 7 and 8; cf. control, lane 6), that is, the commitment to the first template during preincubation required UAF. The converse experiment, preincubation of the first template with UAF followed by the addition of the second template and the rrn10 extracts, showed transcription of the first template and little or no transcription of the second template (Fig. 9, lanes 10 and 11; cf. controls, lanes 9, 12, and 13). These results demonstrate that UAF is apparently bound stably to a template and that UAF is necessary and sufficient for template commitment.

\section{Template competition analysis of promoter deletion mutants}

To define the promoter region responsible for the binding of UAF, we carried out template competition experiments using various $5^{\prime}$ - and $3^{\prime}$-deletion promoters (see Fig. 7b) as the first template for preincubation with UAF. As shown in Figure 10a, a deletion from -208 to -155 partially impaired the ability of the first template to sequester UAF from transcription of the second template (lane 3; in some other experiments, no impairment or only a very weak impairment was observed). Deletions extending to -119 and beyond abolished this ability; that is, transcription of the second template took place without any significant decrease relative to control (Fig. $10 \mathrm{a}$, cf. lanes 4-6 and 7). [It should be noted that $5^{\prime}$ deletion of the first template to -155 decreased the template activity itself only slightly, if any, and deletion to -119 and to -91 caused a very large decrease in the template activity of the first template but did not abolish it; deletion to -26 abolished transcription of the first template completely in this system. Thus, the $5^{\prime}$ boundary of the promoter, as judged by template activity (not by competition activity), is between -155 and -119 , and the boundary between the upstream and core elements is somewhere between -91 and -26 . These results are very similar to the results of previous analyses (Musters et al. 1989; Kulkens et al. 1991; Choe et al. 1992; see legend to Fig. 10).]

Similar template competition experiments were also carried out by a series of 3 '-deletion mutants of the first template. The ability to bind UAF, and thus prevent transcription of the second template, was not significantly affected when the promoter was deleted to -41 from downstream, even though the template activity was lost when the deletion extended to -2 and beyond into the core region (Fig. 10b, lanes 4-6; see legend). When the deletion extended to -70 and beyond, the ability of the first template to bind UAF was lost, and transcription of the second template took place to ap- 


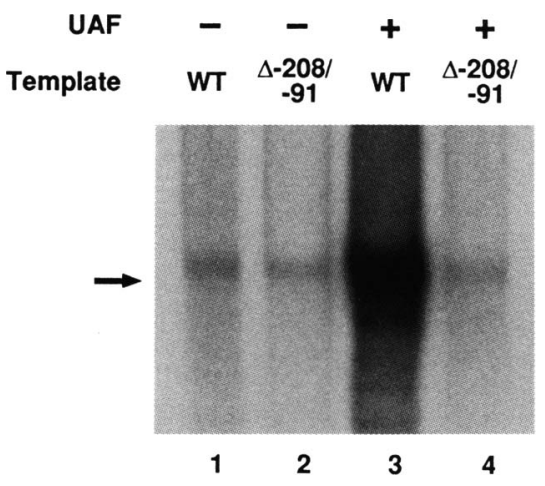

Figure 8. Effects of UAF on transcription of rDNA using template with or without the upstream element. In vitro transcription reactions were carried out using $\operatorname{rrn} 10$ mutant extract with or without addition of purified UAF $(0.6 \mu l$ of Superose peak fraction). pSIRT is the template used in lanes 1 and 3 (wild-type promoter). pSIRT $\Delta-208 /-91$, which contains an internal deletion removing an upstream promoter sequence, is the template used in lanes 2 and 4. Relative amounts of ${ }^{32}$ P-labeled nucleotide incorporated into specific transcripts were quantitated using a PhosphorImager. The values obtained were 1.0, $0.74,10.1$, and 0.50 for lanes $1-4$. In other experiments, relative levels of specific transcripts were quantitated by densitometric analysis of autoradiographs. Similar results were obtained, and the degree of stimulation by UAF for the wild-type promoter ranged from $\sim 10$ - to $\sim 25$-fold. We note that the two templates used contain the 5S RNA gene (see Fig. 7a), and that the amounts of 5S RNA transcripts produced in the same reactions were not significantly different among the four reactions (not shown herel, thus serving as an internal control in these experiments.

proximately the same degree as the control (Fig. 10b, cf. lanes 7-9 and 10). These experiments define the region (5' border near $-155 ; 3^{\prime}$ border between -70 and -41 ) that is required for the stable binding of UAF leading to template commitment.

\section{Discussion}

\section{$U A F$ is a Pol I transcription factor that is not essential but stimulatory}

Experiments described in this paper demonstrate that the three proteins, Rrn5p, Rrn9p, and Rrn10p, encoded by $R R N 5, R R N 9$, and $R R N 10$, respectively, are components of a multiprotein complex that functions as a transcription factor in rDNA transcription by Pol I. First, the complex has been purified both from a strain expressing HAl-tagged RRN5 and from a strain expressing HAltagged $R R N 9$, by procedures that include a specific immunoaffinity purification step followed by three column chromatography steps, and the presence of Rrn5p, Rrn9p, and Rrn 10p (together with two additional proteins) was demonstrated in both instances. In addition, the purified complex had the ability to stimulate transcription by three different extracts prepared from rrn5, rrn9, and rrn10 mutants, respectively. Therefore, it is clear that these three different mutant extracts are deficient in Pol I transcription activity because they lack this transcrip- tion factor complex. As mentioned above, we call this complex UAF.

In contrast to extracts prepared from rrn6 and $r m 7$ disruption mutants (Keys et al. 1994), where no rDNA transcription activity was detectable, extracts prepared from $r r n 5, r r n 9$, and $r m 10$ disruption mutants all showed very weak, but detectable activity to transcribe rDNA specifically. Thus, the UAF complex is not absolutely required for rDNA transcription in vitro, but serves as a stimulatory factor. This conclusion also appears to apply to rDNA transcription in vivo. As shown in this paper, the RRN5, RRN9, and RRN10 genes are not absolutely required for cell growth, whereas the $R R N 7$ and $R R N 6$ genes are essential (Keys et al. 1994). The difference between the two groups of Pol I transcription factor genes is almost certainly attributable to the presumed difference in the requirements of their gene products for rDNA transcription in vivo. To confirm this presumed difference, we carried out in vivo pulse-labeling experiments. Disruption mutant strains $\Delta \mathrm{rrn} 5, \Delta \mathrm{rrn} 9$, or $\Delta$ rrn10, which carry the pGAL7-35S rDNA fusion gene on plasmid pNOY103, were grown in galactose media, shifted to glucose media, and then incorporation of $\left[{ }^{3} \mathrm{H}\right]$ uridine into large rRNAs was examined and compared with the $\Delta \operatorname{rrn} 7$ strain carrying the same pGAL7$35 \mathrm{~S}$ rDNA fusion gene on pNOY103. We observed very weak but definite synthesis of ${ }^{3} \mathrm{H}$-labeled $18 \mathrm{~S}$ and $25 \mathrm{~S}$ rRNAs in glucose for the former three disruption $(\Delta \operatorname{rrn} 5$, $\Delta \mathrm{rrn} 9$, and $\Delta \mathrm{rrn}$ l0) strains, while the synthesis of these rRNAs was undetectable for the $\Delta \mathrm{rrn} 7 \mathrm{strain}(\mathrm{M}$. Nomura et al. unpubl.; see also Fig. 1 and the legend). It should be noted that in previous experiments using an rrn 7 mutant (as well as an rrn6 mutant), weak but definite synthesis of $18 \mathrm{~S}$ and $25 \mathrm{~S}$ rRNAs was observed (Nogi et al. 1991). The rrn 7 mutant (rrn7-1) used in the previous work carries an amber mutation changing a glutamine codon at 250 to a stop codon (D.A. Keys et al., unpubl.), whereas the rrn 7 mutant used in the new experiments carries a deletion (rrn7D::LEU2). Perhaps more importantly, the repression of the GAL7-35S rDNA fusion gene in the previous experiments was done by the addition of glucose to galactose medium without removing galactose, whereas in the new experiments repression was achieved with glucose in the absence of galactose, leading to presumably much stronger repression than in the previous experiments. These differences may explain the difference in (the degree of) residual rRNA synthesis in $r r n 7$ mutants between the previous and the new experiments. Because of uncertainty in the degree of the residual transcription of rDNA by Pol II in this system combined with very weak rRNA synthesis in these deletion mutants in glucose media, it is difficult to definitively prove the above-mentioned proposition, namely that Rrn6p and Rrn 7p are absolutely required for Pol I transcription, whereas the requirement of Rrn5p, Rrn9p or Rrn 10p for rDNA transcription by Pol I is more relaxed in vivo. Nevertheless, $\left[{ }^{3} \mathrm{H}\right]$ uridine pulse-labeling experiments like that shown in Figure 1 tend to support this proposition.

Even though RRN5, RRN9, and RRN10 are not abso- 
(a)

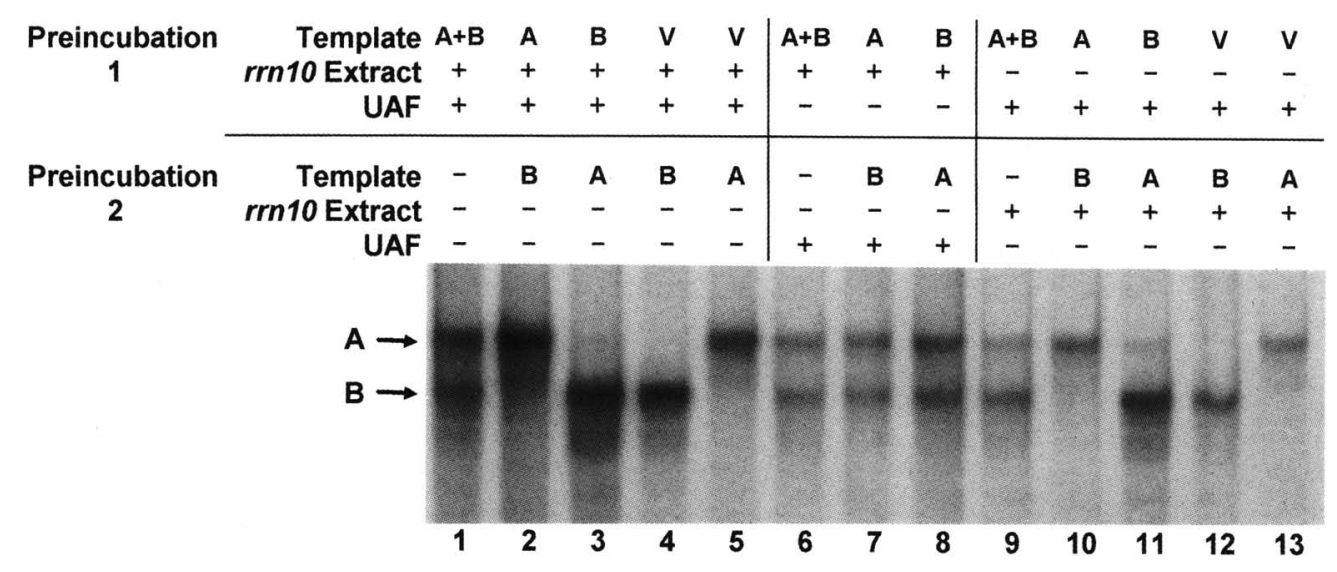

(b)

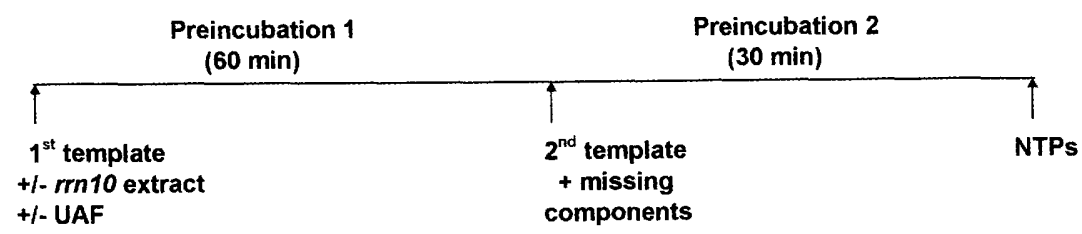

Figure 9. Formation of a committed UAF-template complex. Template commitment experiments were performed using rrn10 mutant extract and purified UAF (a Superose peak fraction) as outlined in $b$. The mutant extract and purified UAF together (lanes 1-5) or individual fractions (mutant extract; lanes 6-8, or purified UAF; lanes 9-13) were preincubated with the first template (400 ng) for $60 \mathrm{~min}$. The second template (400 ng) was then added, together with rm10 extract or UAF that was omitted during the first preincubation, as indicated. After a second preincubation of 30 min nucleoside triphosphates (NTPs) were added, and transcription was allowed to proceed for $40 \mathrm{~min}$. RNA was analyzed by urea-PAGE followed by autoradiography $(a)$. Template A is pSIRT giving a specific transcript of 765 nucleotides; template B is pSIRT $\Delta+39 /+128$, giving a specific transcript of 675 nucleotides. The positions of these two transcripts are indicated as A and B, respectively. In lanes 4 and 5 and 12 and 13 , preincubation with $\mathrm{rrn} 10$ extract and/or UAF was done using nonspecific DNA (pBluescript vector DNA; indicated as V) followed by the addition of rDNA template to show that the absence of transcription of the second added template (in lanes 2 and 3 and 10 and 11) is attributable to specific and stable binding of UAF to the first rDNA template.

lutely essential genes and the UAF complex containing the encoded proteins is not absolutely required for in vitro rDNA transcription, the degree of stimulation by UAF observed in vitro is large, ranging from $\sim 10$ - to $\sim 25$-fold stimulation. The stimulation provided by UAF in vivo might even exceed this increase. In the experiments mentioned above (see legend to Fig. 1), one can calculate reduction in large rRNA synthesis in $\Delta \mathrm{rrn} 10$ (or $\Delta \mathrm{rrn} 5$ or $\Delta \mathrm{rrn} 9$ ) strains. Disregarding the contribution of residual rDNA transcription by Pol II in glucose media and normalizing to the sum of 5S RNA and tRNA synthesized by Pol III, we can conclude, for example, that the reduction of rRNA transcription in the $\Delta \mathrm{rrn} 10 \mathrm{mu}$ tant is $\sim 93 \%$. Thus, UAF, though not essential, appears to play an important function in rDNA transcription in vivo.

\section{UAF mediates stimulation by the upstream element}

We have demonstrated that the large stimulation by the upstream element is mediated by UAF; with a template lacking the upstream element, UAF does not give any significant stimulation of transcription by Pol I, and conversely, in the absence of UAF, the upstream element does not confer any significant stimulation. It appears that UAF is the factor essential for stimulation by the upstream element, and no other component (in our extracts) can replace UAF to mediate the stimulation.

We have also demonstrated that UAF binds to the upstream element and commits that template to transcription. Our experiments show that UAF is necessary and sufficient for template commitment and therefore defines the basis of stimulation of transcription by the upstream element mediated by UAF in our in vitro transcription system. Of course, our in vitro system uses arbitrarily defined "crude extracts" (D-300 plus PC-300 fractions) and may be missing some important factors that might also be capable of stimulation by land/or binding tol the upstream element. However, we think that such factors, even if present, might carry out perhaps a secondary role and will not be able to substitute for the role of UAF. This argument is based on the fol- 
(a)

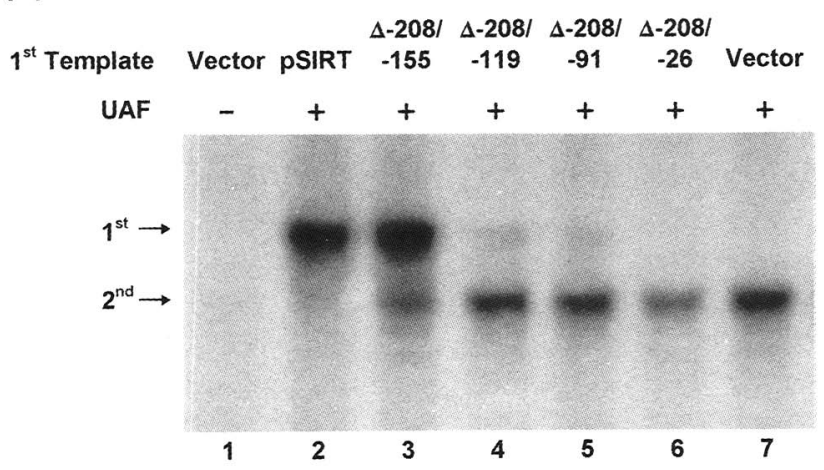

(b)

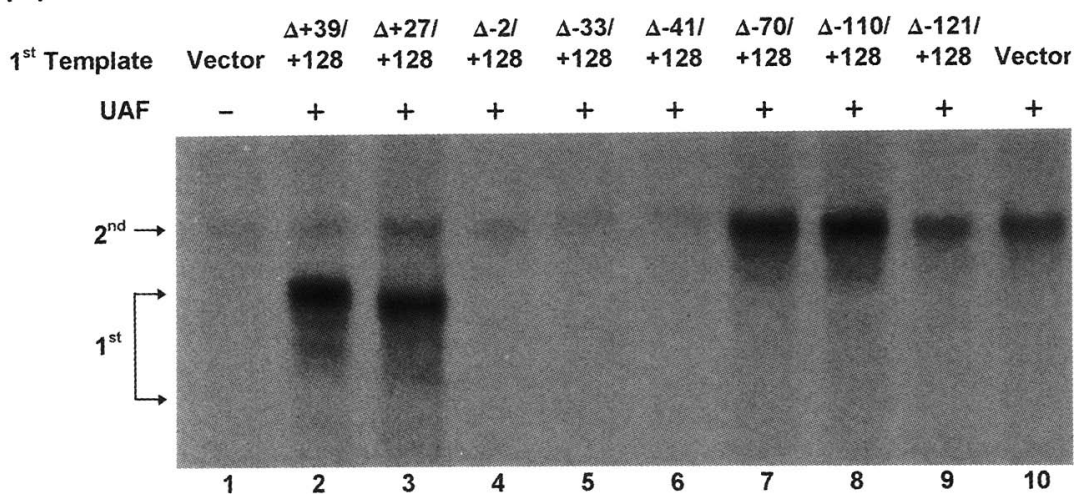

(c)

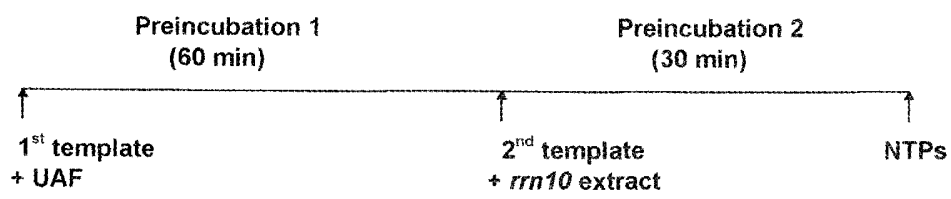

Figure 10. Template competition analysis of promoter mutants to define the region required for the stable association of UAF with the rDNA template. Template competition experiments were performed as diagramed in c. Purified UAF $(0.6 \mu l$ of Superose peak fraction) was preincubated with the first DNA template (400 ng). Then a second wild-type DNA template $(200 \mathrm{ng}$ ) was added together with mutant rrn10 extract, and after a second preincubation, nucleoside triphosphates were added to allow transcription to begin. A series of $5^{\prime}$-promoter deletions were used as first template in $a_{\text {; }}$ a series of $3^{\prime}$-promoter deletions were used in $b$. The second template in $a$ is pSIRT $\Delta+39 /+128$, containing a wild-type promoter and generating a specific transcript of 675 nucleotides, 90 nucleotides shorter than the transcript generated from the 5'-promoter deletion mutants, when they are active. The second template in $b$ is pSIRT (wild type), which generates a transcript of 765 nucleotides that is longer than the transcripts produced from transcriptionally active 3 '-deletion mutants used as the first template. It should be noted that longer 3 ' deletions are expected to produce correspondingly shorter transcripts when they are active. Thus, the transcripts from the first templates seen in lanes 2 and 3 in $b$ are expected to be 90 nucleotides and 102 nucleotides, respectively, shorter than the transcript from the second template. Note that templates used for lanes 4-6 had the ability to sequester UAF, yet failed to produce any transcripts. The latter result is consistent with the results of previous analyses to define the $3^{\prime}$ boundary of the promoter (see text). Nonspecific DNA (400 ng pBluescript vector DNA) was used in the first preincubation in lanes 1 and 7 in $a$, and lanes 1 and 10 in $b$. UAF was omitted from the reaction in lanes 1 of $a$ and $b$. lowing observations: First, the degree of stimulation by the upstream element observed in vivo (by at least a factor 5 ; done by the use of plasmids carrying a minigene and its deletion mutants; see Musters et al. 1989) can be accounted for by the stimulation observed by the present in vitro system (by a factor of 10-25); second, in vivo $\left[{ }^{3} \mathrm{H}\right]$ uridine incorporation experiments using $\operatorname{rrn} 5, \operatorname{rrn} 9$, and rrn10 mutants directly demonstrate a major and specific role of these gene products in rDNA transcription by Pol I, and calculation shows that UAF stimulates rDNA transcription in vivo by at least a factor of $\sim 15$ (see the preceding section); and third, rrn5, rrn9, and rrn10 disruption strains show a severe reduction in their growth rates, although they are still able to form colonies, and their growth defects can be substantially overcome by a helper plasmid carrying the pGAL7-35S rDNA fusion gene, indicating again the importance of these genes in Pol I function in vivo.
The upstream region required for stable binding of $U A F$

Experiments using various deletion mutant templates have clearly defined the upstream region of the promoter required for the stable binding of UAF. The $5^{\prime}$ boundary of this region is near -155 , and the $3^{\prime}$ boundary is between -41 and -70 . Previously we carried out similar template commitment experiments using crude extracts and obtained the evidence for the presence of a factor (which is now identified as UAF) interacting with the upstream region (Kulkens et al. 1991). The results were generally similar to the present one. However, there are some discrepancies in defining the $5^{\prime}$ and the $3^{\prime}$ boundaries of the region responsible for template commitment. In the previous study, a deletion extending to -119 showed a partial (not a full) reduction in the ability to bind the factors, and a more extensive deletion was re- 
quired to achieve full reduction. Similarly, the $3^{\prime}$ deletion extending to -70 caused a full reduction in the ability to bind UAF in the present study, whereas the same deletion did not cause such a reduction and deletion had to go further to achieve a full reduction. The differences are probably derived from the use of highly purified UAF in the present experiment for preincubation with the first template, whereas crude extracts were used in the previous studies. Thus, in the absence of other components, UAF may interact only weakly with the $3^{\prime}-\Delta-70 /+128$ template. Other factors whose binding depends on the binding of UAF may join and stabilize formation of the preinitiation complex containing UAF and the DNA template, leading to the removal of UAF (and other factors) from the second template in experiments using crude extracts but not in the present experiments. A similar explanation can also be made for the results obtained for the 5 -end deletion mutations in the previous experiments which used crude extracts. In this regard, it should be noted that the Rrn6/7 complex was shown previously not to bind stably to the rDNA template by itself but to join a stable preinitiation complex in the presence of other factors present in the extracts made from rrn6 (or rrn7) deletion mutants (Keys et al. 1994). Thus, the Rrn6/7 complex, alone or together with other factors, might strengthen the initial interaction of UAF with DNA template.

In the previous mutational analyses of the promoter both in vivo and in vitro, the upstream region important for transcription of the yeast Pol I promoter was divided into two regions, domain II and domain III, and the core element was called domain I (Musters et al. 1989; Kulkens et al. 1991). The basis for defining separate domains in the upstream region was provided by linker scanning mutations between domains II and III, which had no significant effects on transcription activity or on competition ability in template competition experiments (Musters et al. 1989; Kulkens et al. 1991). However, there was no clear functional basis to separate these two domains, and UAF appears to interact with the region covering both domains. Thus, in agreement with Choe et al. (1992), we will now call the region covering both domain II and III simply the upstream element. Thus, defined in this way, the region necessary for the stable binding of UAF appears to roughly correspond to the upstream element.

\section{Comparison of $U A F$ with $U B F$ in other eukaryotic systems}

As stated above, UBF isolated from other eukaryotic systems interacts with the upstream element and has been considered to be the mediator of the stimulatory activity of this cis-acting element. Like the upstream element, both protein factors UAF and UBF are only stimulatory and are not absolutely required. Thus UAF and UBF are similar in these respects. However, there are several significant differences between the two. First, the interaction between UAF and the upstream element appears to be strong enough to be able to commit the template for transcription. Our experiments have demonstrated not only that UAF alone is sufficient but also that UAF is necessary for template commitment. In the case of other systems, UBF alone does not appear to be sufficient for template commitment. In the mouse system, TIF-IB (SL1) alone, but not mUBF (mouse homolog of UBF) alone, is able to form a template-committed complex, whereas mUBF acts to stimulate the formation of such committed complexes (Schnapp and Grummt, 1991). In the Xenopus system, McStay et al. (1991) have concluded that XUBF (Xenopus homolog of UBF) and Rib1 (Xenopus homolog of SL1) are both required for template commitment. In the rat system, the presence of rUBF (rat homolog of UBF) appears to stimulate the formation of a template-committed complex (Smith et al. 1990), but the published data do not allow an answer to the question of whether rUBF alone is sufficient for template commitment, nor the question of whether it is necessary for template commitment.

The second difference between UBF and UAF is that UAF does not appear to make a significant interaction with the core element region, whereas UBF appears to interact with the core in addition to the upstream element. This was demonstrated for human (e.g., Bell et al. 1988), rat (Pikaard et al. 1990), and Xenopus (Bell et al. 1989; Pikaard et al. 1989,1990; Read et al. 1992; Leblanc et al. 1993). It was shown that UBF significantly stimulates transcription of rDNA even using a mutant template missing the upstream element entirely, although to a lesser extent as compared with the wild-type template (Bell et al. 1988). In contrast, no significant stimulation of rDNA transcription by UAF was observed with a template missing the upstream element in the yeast system nor could such a deleted template sequester UAF in template competition experiments.

The third and perhaps a most obvious difference is their structures. Whereas UBF is a homodimer, UAF consists of at least three and possibly five different proteins, three of which, Rrn5p, Rrn9p, and Rrn10p, have no sequence resemblance to UBF. The UBF polypeptide consists of five to six copies of the HMG box with the amino-terminal domain required for dimerization and a highly acidic carboxy-terminal domain. These structural features, including the primary sequences, are highly conserved from Xenopus to human (Jantzen et al. 1990, 1992; Bachvarov and Moss, 1991; McStay et al. 1991; O'Mahony et al. 1991). No such sequence feature is present in Rrn5p, Rrn9p, or Rrn10p. In addition, these three proteins as well as two other proteins in the purified UAF preparation did not cross-react with antibodies raised to Xenopus UBF or antibodies to a yeast HMG box protein, NHP6A (D.A. Keys et al., unpubl.; for NHP6A, see Kolodrubetz and Burgum 1990). UBF is a DNA-binding protein with low sequence specificity (Copenhaver et al. 1994; Hu et al. 1994), and its activity in rDNA transcription almost certainly depends on its ability to bend and wrap DNA carried out by the dimerization domain and one or more of the HMG box domains (Bazett-Jones et al. 1994; Putnam et al. 1994). Thus, the absence of an HMG box in any of the three characterized subunits of 
UAF is significant. Of course, it is still possible that the other uncharacterized components might contain the HMG box, and the exact comparison of structures of these two transcription factors, UBF and UAF, must await cloning and sequencing of the genes for $\mathrm{p} 30$ and p18. Nevertheless, it should be noted that the three proteins, Rrn5p, Rrn9p, and Rrn10p, which are all essential for the function of UAF as a Pol I transcription factor, together comprise most of the mass of UAF. UBF does not have any domain resembling these proteins. Thus, it would be very remarkable if UAF is a functional yeast homolog of UBF.

As discussed earlier, UAF appears to initiate assembly of the transcription-competent preinitiation complex by recruiting other factors including the Rrn6/7 complex, which together with TBP may represent a functional yeast homolog of SL1 (Keys et al. 1994). UAF does not resemble UBF; rather its complexity resembles TFIIIC in Pol III transcription systems, which recruits TFIIIB, the essential Pol III transcription factor containing TBP, and which contains multiple protein subunits (six in the yeast TFIIIC, and five in the human TFIIIC2; for review, see Willis, 1993; Geiduschek and Kassavetis 1995).

As emphasized by Choe et al. (1992) and also discussed in this paper, general structural features of rDNA promoters are well conserved between the yeast promoter and the metazoan promoters from frog to human, suggesting a conservation of mechanisms of initiation used by Pol I transcriptional machineries. Thus, the question of whether UAF is really a functional homolog of UBF is important and deserves further investigation. In this connection, it should be noted that UBF was reported to be complexed with TBP in TFIID fractions and to play a role in Pol II transcription (Kwon and Green 1994). It should also be noted that UBF is an abundant nuclear protein found mostly in the nucleolus (Chan et al. 1991; Roussel et al. 1993; Zatsepina et al. 1993), and its amount was reported to be $\sim 50,000$ copies per cell; these levels are in great excess of the $\sim 200$ copies of the rRNA gene and 100-400 copies of the SL1 molecules per cell (Bell et al. 1988; see also McStay et al. 1991). In our yeast system, the amount of UAF is comparable to that of the Rrn6/7 complex, which is approximately a few hundred per cell (D.A. Keys et al., unpubl.), compared with $\sim 120$ copies of the rRNA gene per cell. Thus, it is possible that UBF might have some other functions besides recruitment of SLl at the rRNA gene promoter (and enhancer). It has been suggested (Putnam et al. 1994) that UBF might play a structural role by binding to DNA in the nucleolus and displacing nucleosomes or preventing nucleosome assembly, thereby maintaining rDNA free from repression mediated by histones and some other repressors (Kuhn and Grummt 1992; Kuhn et al. 1993).

In the case of UAF, the functions of the three genetically characterized subunits, Rrn5p, Rrn9p, and Rrn10p, are specifically in rDNA transcription, as judged by the in vivo genetic experiments; a severe growth defect caused by disruption of any of the genes for these subunits can be remedied (though partially) by transcription of the pGAL7-35S rDNA fusion gene by Pol II. $\left[{ }^{3} \mathrm{H}\right]$ uri- dine pulse-labeling experiments using $r r n 5$, $r r n 9$, and rrn10 mutants have also directly demonstrated a specific in vivo function of these proteins in rDNA transcription by Pol I. These in vivo experiments, combined with the in vitro experiments presented in this paper, provide unequivocal evidence that UAF is a Pol I-specific transcription factor interacting with the upstream element of the yeast Pol I promoter. So, in view of many clear differences between UAF and UBF discussed above, it appears that there are two alternative possibilities. One is that yeast and higher eukaryotes use very different transcription factors to mediate the stimulatory activity of the upstream element. The other possibility is that a multiprotein transcription factor similar to the yeast UAF is also present in higher eukaryotes and has not been discovered so far. This second possibility may deserve serious experimental investigation.

\section{Materials and methods}

Media, buffers, strains, and plasmids

YEP-glucose medium, YEP-galactose medium, synthetic galactose medium, and synthetic glucose medium were described previously (Nogi et al. 1991; Keys et al. 1994).

The strains and plasmids used in this study are listed in Table 1. To construct the diploid strain NOY610, the haploid strain NOY423 was first transformed with plasmid p43A, carrying the HO gene (Harashima et al. 1984). One of the transformants was subsequently cured of the resident plasmid, assayed for its ability to sporulate, and named NOY610. Other procedures used for HAl epitope tagging and gene disruption are described below.

\section{Cloning and sequencing of RRN5, RRN9, and RRN10}

Strains NOY697, NOY698, and NOY696 were used to clone $R R N 5, R R N 9$, and RRN10 genes, respectively. For cloning of $R R N 5$ and $R R N 9$, the yeast genomic library (Nakayama et al. 1985) carrying chromosomal DNA inserted at the BamHI site of YCPN1 vector (CEN3 ARS1 TRP1) was used, and for cloning of $R R N 10$, the YEp213-based yeast genomic library (Hasegawa et al. 1989) was used. DNA sequences of pertinent fragments were determined by the dideoxy method with the Tag DyeDeoxy Terminator Cycle Sequencing Kit (Applied Biosystems, Foster City, CA).

Construction of $\operatorname{rrn} 5, \operatorname{rrn} 9$, and $\operatorname{rm} 10$ deletion mutants

Two disruption mutants were constructed: one is an insertion of an 850-bp DNA fragment carrying TRP1 at the ClaI site within RRN5 (rrn5::TRP1; see Fig. 2a for the ClaI site), and the other is a deletion replacing the region between NcoI and XhoI within RRN5 by LEU2 (rrn5A::LEU2; see Fig. 2b). To construct the rrn5::TRP1 allele, the $3.3-\mathrm{kb}$ HindIII fragment carrying RRN5 obtained from pNOY230 was inserted into the HindIII site of pUC19. This plasmid was digested with ClaI, and the 850-bp ClaI-BgIII fragment carrying TRP1 was inserted at the ClaI site by a blunt-end ligation. The resultant plasmid was digested with $\mathrm{KpnI}$ and $\mathrm{NaeI}$ and the $1.5 \mathrm{-kb}$ fragment containing rrn5::TRP1 was transformed into NOY424, which is $\operatorname{trp} 1$ and carries pNOY103, selecting $\operatorname{Trp}^{+}$transformants on a galactose plate. One of the transformants, NOY577, can grow on galactose without losing pNOY103 but grows very poorly on glucose. To construct the rrn5A::LEU2 allele, a plasmid (pNOY3231) 
carrying a 1.9-kb HindIII-BamHI fragment containing the RRN5 gene in pUC19 was digested with $\mathrm{NcOI}$ and $\mathrm{Xhol}$, which resulted in an internal deletion of RRN5 (see Fig. 2b). The deleted region of the RRN5 gene in pNOY3231 was replaced with a $2.2 \mathrm{~kb}$ XhoI-SalI fragment containing the LEU2 gene (which was obtained from pNOY3114) by a blunt-end ligation. The resulting plasmid was digested with BamHI and Ndel, which released the $3.4-\mathrm{kb}$ fragment carrying $\operatorname{rrn} 5 \Delta:: L E U 2$. This fragment was transformed into diploid strain NOY397. Leu ${ }^{+}$transformants were selected and NOY679, which is one of the transformants, was confirmed by tetrad analysis to contain one copy of the RRN5 gene replaced by the LEU2 gene.

A 2.2-kb BamHI-SphI fragment containing RRN9 (see Fig. 2c) derived from pNOY187 was ligated between the BamHI and SphI sites of pUC19. The resulting plasmid was cut with SalI and EcoRV to remove $612 \mathrm{bp}$ of the RRN9-coding region, blunted with T4 DNA polymerase, and then ligated with a blunted 600-bp BamHI fragment containing HIS3 (see Fig. 2d). The resulting plasmid containing the HIS 3 fragment replacing the RRN9 SalI-EcoRV fragment was digested with SspI and the 1.5 -kb fragment containing $r m 9 \Delta:: H I S 3$ was transformed into diploid strain NOY397, selecting for $\mathrm{His}^{+}$transformants. One of the transformants, NOY678, was confirmed by tetrad analysis to carry rrn $94:: H I S 3$ on one chromosome.

A $3.3-\mathrm{kb}$ BamHI-HindIII fragment containing RRN10 was isolated from pNOY337 and ligated between the BamHI and HindIII sites of pUC19. The resulting plasmid was digested with PstI and partially digested with XhoI to remove a 478-bp PstIXhoI fragment, and then blunted using Escherichia coli DNA polymerase (Klenow fragment). A blunted 2.2-kb SalI-XhoI fragment containing LEU2 was inserted between the original PstI and $X$ hoI sites of $R R N 10$ \{see Fig. 2f). The resultant plasmid was digested with BamHI-HindIII, and the fragment carrying rrn104::LEU2 was transformed into dipolid strain NOY610, selecting for $\mathrm{Leu}^{+}$transformants. One of the transformants, NOY677, was confirmed by tetrad analysis to carry the expected rrn104::LEU2 on one chromosome.

\section{Construction of pNOY330, encoding (HA1) ${ }_{3}$-tagged Rrn5p}

A 1.6-kb RRN5 fragment was synthesized by PCR amplification using an oligonucleotide, which hybridizes at a position $\sim \mathbf{4 7 0}$ nucleotides upstream of the initiator methionine codon and introduces a unique SalI site at one end of the PCR product, and another oligonucleotide, which hybridizes at a position near the stop codon and introduces a sequence (GGCGGCCGC) containing a unique NotI site (underlined) following the last amino acid (lysine) codon (AAA) of RRN5 at the other end. pNOY230 was used as template for the PCR reaction. After cutting with SalI and NotI, the PCR product was ligated between the SalI and NotI sites of pNOY328, a LEU2-marked CEN plasmid, to create pNOY329, which contains a full-length RRN5 including its native promoter with a unique NotI site at the 3 ' end of the RRN5 coding region. A $0.12-\mathrm{kb}$ NotI-SacI fragment encoding three tandem copies of the 9-amino-acid HAl epitope (followed by Ala-Gln-Cys-Stop) was isolated from pNOY3220 (see below) and ligated between the NotI and SacI sites of the above plasmid (pNOY329) to generate pNOY330, fusing the (HA1) $)_{3}$-epitope coding sequence in-frame to the sequence encoding the carboxyl terminus of Rrn $5 \mathrm{p}$. The plasmid, pNOY330, constructed in this way encodes $(\mathrm{HAl})_{3}-\mathrm{Rrn} 5 \mathrm{p}$, which has 38 additional amino acids [GGRIF(HAl)G(HAl)GS (HAl) AQC; $\mathrm{HAl}$ is a 9-amino-acid HAl-epitope sequence, YPYDVPDYA] at the end of Rrn5p.

Plasmid pNOY3220 is a convenient source for the NotI-SacI fragment encoding three tandem copies of the HAl epitope used above and was constructed by PCR using GTEP1 (Roof et al. $1992)$ as template, modifying the $\mathrm{Not}-(\mathrm{HAl})_{3}-\mathrm{NotI}$ structure present in GTEP1 to the NotI-(HA1) $\left.\right|_{3}-$ SacI structure; the distal end is now GCTCAGTGCTAGAGCTC (encoding AQC and the stop codon TAG overlapped with the SacI site which is underlined) rather than GCTCAGTGCGGCCGC (encoding the AQC followed by the NotI site underlined). The PCR product was digested with NotI and SacI, and the fragment was cloned between the NotI and SacI sites of pBluescript KS|+ ), yielding pNOY3220.

\section{Construction of pNOY332, which encodes $\left(\mathrm{HA1}_{3}\right)_{\text {-tagged }}$} Rrn9p

The 837-bp EcoRI-SalI DNA fragment containing the $3^{\prime}$ end of the RRN9 coding region and the downstream untranslated region (-AACATATGAATGAGA-; the stop codon underlined) was first subcloned into a pUC19 plasmid. The oligonucleotide GGCGGCCGC (the NotI site underlined) was introduced between the codon for the last amino acid (ATA for Ile) and the stop codon (TGA) of RRN9 by PCR reaction. A BsmINaeI fragment, which now carries the $3^{\prime}$ end of RRN9 containing the NotI site, was then used to replace the corresponding BsmI-NaeI fragment in the wild-type RRN9 gene carried on plasmid pNOY335, resulting in pNOY336. Finally, the 114-bp NotI fragment containing $(\mathrm{HAl})_{3}$ prepared from GTEP1 was inserted into pNOY336. The resultant plasmid, pNOY332, encodes (HAl) $)_{3}-$ Rrn9p, which has 40 amino acids [GGRIF(HAl) G(HAl)GS(HA1)AQCGR)] at the end of Rrn9p.

It should be noted that pNOY330 and pNOY332 complement rrn $5 \Delta:: L E U 2$ and $r m 9 \Delta:: H I S 3$, respectively, indicating that triple-HAl tagging of Rrn5p or Rrn9p at the end of the carboxyl terminus does not apparently affect the functions of these proteins.

\section{Polyclonal antibodies against Rrn5p, Rrn9p, and Rrn10p}

Rrn5p, Rrn9p, and Rrn10p were isolated as fusion proteins to prepare polyclonal antibodies against these proteins. An RRN5 gene with a unique $B g I I I$ site upstream of the start codon and a unique BamHI site downstream of the stop codon was synthesized by PCR amplification and was inserted into the BamHI site of the expression vector pNO3124 /pATH23; see Koerner et al. 1991), fusing full-length RRN5 coding sequence in-frame with the carboxy-terminal coding region of $\operatorname{trpE}$. TrpE-Rrn5p fusion protein was expressed in $E$. coli $\mathrm{DH} 5 \alpha$ cells containing this plasmid, and isolated by extraction of insoluble membrane/ wall pellets with SDS followed by preparative SDS-PAGE.

A $0.77-\mathrm{kb}$ HincII fragment encoding amino acids 54-310 of $R R N 9$ was inserted into the SmaI site of the expression vector pGEX-3X (Pharmacia), fusing the RRN9 fragment in-frame with the carboxy-terminal coding region of glutathione $S$-transferase (GST). The GST-Rrn9p fusion protein was isolated as an insoluble precipitate from $E$. coli cells and purified by a preparative SDS-PAGE.

A 2.6-kb PstI-SalI RRN10 fragment was isolated from pNOY337 and inserted between the PstI and Sall sites of pRS315, placing BamHI and SmaI sites immediately upstream of the PstI site. A $2.0-\mathrm{kb}$ BamHI-HindIII RRN10 fragment was then isolated from this plasmid and inserted between the BamHI and HindIII sites of the expression vector pET15b/Novagen), fusing the $\mathrm{His}_{6}$-tagged coding sequence (MGSSHHHHHHSSGLVPRGSHMLEDPPG) in-frame to codon 9 of RRN10, generating plasmid pNOY3233. His-tagged Rrn10p was affinity purified from an E. coli strain containing pNOY3233 using a $\mathrm{Ni}(\mathrm{II}) \mathrm{SO}_{4}$ column, followed by preparative SDS-PAGE. Using 
these fusion protein preparations, rabbit polyclonal antibodies were produced by Bethyl Laboratories (Texas).

\section{Purification of $(\mathrm{HA1})_{3}-$ Rrn $5 p$ and $(\mathrm{HA1})_{3}-\mathrm{Rrn} 9 \mathrm{p}$ complexes}

Monoclonal antibody 12CA5, specific to the HA1 epitope, and the epitope peptide (YPYDVPDYA) were obtained from Berkeley Antibody Co. (Richmond, CA). The 12CA5 antibody was cross-linked to protein G-Sepharose (Pharmacia) using dimethyl pimelimidate according to the protocol provided by the supplier of the reagent. Extracts were prepared from 50-100 grams of cells from strains expressing $(\mathrm{HAl})_{3}$-tagged Rrn5p (NOY662) or (HAl) $)_{3}$-tagged Rrn9p (NOY674). Cells were homogenized in $350 \mathrm{ml}$ of buffer containing $400 \mathrm{~mm}$ ammonium sulfate, $200 \mathrm{~mm}$ Tris-acetate $\{\mathrm{pH} 8.0\}, 10 \%$ glycerol, $10 \mathrm{~mm} \mathrm{Mg}$ acetate, $10 \mathrm{~mm} \beta$-mercaptoethanol, $1 \mathrm{~mm}$ PMSF, $0.1 \%$ Tween 20 , and $5.5 \mathrm{~mm}$ benzamidine- $\mathrm{HCl}$, plus $150 \mathrm{ml}$ of acid-washed glass beads (0.4-0.5 mm diam.) using a $400 \mathrm{ml}$ Bead-beater apparatus (Biospec Products, Bartlesville, OK), with 30 pulses of 30 sec with a 90 sec pause between each pulse at a reduced voltage of $95 \mathrm{~V}$. After centrifugation at $30,000 \mathrm{rpm}$ for $30 \mathrm{~min}$ in a Beckman type Ti-35 rotor, the supernatant was added to $5 \mathrm{ml}$ of protein G-Sepharose beads carrying cross-linked 12CA5 antibodies $(\sim 20 \mathrm{mg}$ of $\mathrm{IgG} / \mathrm{ml})$, together with $10 \mu \mathrm{g} / \mathrm{ml}$ of the following protease inhibitors: aprotinin, chymostatin, leupeptin, antipain, bestatin, and pepstatin. The antibody beads and supernatant were rolled gently in a bottle on a roller drum for $4 \mathrm{hr}$ at $4^{\circ} \mathrm{C}$. The supernatant was then gently pulled off, and the antibody beads were washed batchwise five times with $50 \mathrm{ml}$ of TA buffer [ $20 \mathrm{~mm}$ Tris-acetate $(\mathrm{pH} 8.0), 0.2 \mathrm{~mm}$ EDTA, $10 \mathrm{~mm} \mathrm{Mg}$ acetate, $10 \mathrm{mM} \beta$-mercaptoethanol, $1 \mathrm{mM}$ PMSF, $20 \%$ glyceroll containing $450 \mathrm{~mm} \mathrm{KCl} \mathrm{(TA/450).} \mathrm{Bound} \mathrm{complexes} \mathrm{were} \mathrm{con-}$ tinuously and simultaneously eluted from the antibody column with $\mathrm{HAl}$ peptide $(1 \mathrm{mg} / \mathrm{ml}$ in TA/450) and loaded directly onto a 5-ml heparin-Sepharose cartridge (HiTrap heparin, Pharmacia) equilibrated in TA/450. This was accomplished by pouring the washed antibody beads into a column, which was in turn connected in series to the heparin column. The flowthrough from the heparin column (containing HAl peptide, which does not bind to heparin) was then recirculated by peristaltic pump back onto the antibody column. The HA1-peptide-containing buffer was circulated through the two columns overnight at $4^{\circ} \mathrm{C}$ at a flow rate of $\sim 1 \mathrm{ml} / \mathrm{min}$. The two columns were then disconnected, the heparin column was washed with several volumes of $T A_{\mathrm{a}} / 450$, and bound proteins were eluted with a salt gradient of $450-1000 \mathrm{mM} \mathrm{KCl}$ in TA buffer. Peak fractions containing HAl-tagged proteins $(\sim 720$ to $\sim 770 \mathrm{mM} \mathrm{KCl})$ were identified by immunoblot analysis using anti-HAl antibody, pooled, diluted to $\sim 375 \mathrm{mM} \mathrm{KCl}$ in TA buffer, and applied to a $1-\mathrm{ml}$ Mono S column equilibrated in TA buffer containing $375 \mathrm{~mm}$ $\mathrm{KCl}(\mathrm{TA} / 375)$. After washing with $\mathrm{TA} / 375$, bound proteins were eluted with a salt gradient of $375-1000 \mathrm{mM} \mathrm{KCl}$ in TA buffer. Peak fractions containing HAl-tagged proteins $\{\sim 550$ to $\sim 600 \mathrm{~mm} \mathrm{KCl}$ ) were pooled, concentrated by Centricon 10 (Amicon) ultrafiltration, and applied to a $25-\mathrm{ml}$ Superose 12 gel filtration column equilibrated in TA buffer containing $10 \%$ glycerol, $450 \mathrm{~mm} \mathrm{KCl}$. The Superose column was run at $0.15 \mathrm{ml} /$ $\mathrm{min}$, and $0.3-\mathrm{ml}$ fractions were collected and stored at $-70^{\circ} \mathrm{C}$.

\section{In vitro transcription reactions}

Transcription extracts [PC-300 /eluting from the phosphocellulose column at $300 \mathrm{~mm} \mathrm{KCl}$ ) and D-300 (eluting from the DEAE column at $300 \mathrm{~mm} \mathrm{KCl}$ ) fractions] were prepared as described previously (Keys et al. 1994) from rrn5-2 mutant strain NOY705, from rrn 9 deletion-mutant strain NOY703, and from rrn10-1 mutant strain NOY696. In vitro transcription reactions were performed as described previously (Keys et al. 1994). Typical in vitro reactions contained, in the $40-\mu$ l reaction volume, 3-6 $\mu$ l of D-300 fraction $\{\sim 20 \mu \mathrm{g}$ of protein) plus 3-9 $\mu \mathrm{l}$ of PC-300 fraction $(\sim 2-4 \mu \mathrm{g}$ of protein) and $200 \mathrm{ng}(5 \mu \mathrm{g} / \mathrm{ml})$ of circular supercoiled DNA template in addition to other standard components. The DNA template used for most assays is pSIRT containing a yeast rDNA minigene that generates a specific transcript of $\sim 765$ nucleotides that is apparently unprocessed and correctly terminated (Keys et al. 1994; for the structure of pSIRT, see Fig. 7a and Musters et al. 1989). For template competition experiments, derivatives of pSIRT containing internal deletions starting at position -208 and extending downstream toward the promoter $\left(5^{\prime}\right.$ deletion series $)$ or starting at position +128 and extending upstream toward the promoter $\left[3^{\prime}\right.$ deletion series) were used, as described previously (see Fig. 7b; Musters et al. 1989; Kulkens et al. 1991). Preincubation of DNA template with purified UAF (Figs. 10 and 9, lanes 9-13) was done in reaction mixture $(10 \mu 1)$ supplemented with $0.4 \%$ BSA. Typical in vitro reactions contained $175 \mathrm{~mm}$ potassium glutamate (no KCl); in vitro reactions using purified $(\mathrm{HA} 1)_{3}-\mathrm{Rm} 5 \mathrm{p}$ or $(\mathrm{HAl})_{3}-\mathrm{Rrn} 9 \mathrm{p}$ complexes (Superose 12 fractions; i.e., purified UAF) were performed with $100 \mathrm{~mm}$ potassium glutamate and 40 $\mathrm{mm} \mathrm{KCl}$, as Superose 12 fractions were not dialyzed to remove the $\mathrm{KCl}$. Reactions were carried out for $40 \mathrm{~min}$ at room temperature, and radioactive RNA synthesized was analyzed by $5 \%$ urea-PAGE followed by autoradiography, as described previously (Keys et al. 1994).

\section{Analysis of RNA labeled in vivo}

Cells were grown in synthetic galactose medium supplemented with casamino acids, tryptophan, and adenosine at $30^{\circ} \mathrm{C}$ to a cell density $\left(A_{600}\right)$ of $\sim 0.2$. Each culture was divided into two parts. To one culture, $\left[{ }^{3} \mathrm{H}\right]$ uridine $(174 \mathrm{mCi} / \mathrm{mmole}, 100 \mu \mathrm{Ci} / \mathrm{ml})$ was added, and after a 60 -min incubation the labeling was stopped by immersing culture flasks into a dry ice-ethanol bath. The other culture was centrifuged, and cells were washed with water and resuspended in synthetic glucose medium with the same supplementation. After incubation at $30^{\circ} \mathrm{C}$ for $1 \mathrm{hr},\left[{ }^{3} \mathrm{H}\right]$ uridinepulse-labeling was carried out in the same way. RNA was isolated and analyzed by electrophoresis on a $2 \%$ polyacrylamide, $0.5 \%$ agarose composite gel followed by autoradiography as described previously (Nogi et al. 1991).

\section{Acknowledgments}

We thank Dr. R.H. Reeder for antibodies against Xenopus UBF, Dr. C.S. Pikaard for a purified preparation of Xenopus UBF, and Dr. D. Kolodrubetz for antibodies against the yeast NHP6A protein. These materials were used in experiments cited as unpublished experiments in this paper. We also thank Dr. J.S. Steffan for discussion, and Drs. S. Sandmeyer, M.L. Waterman, and J. Keener for critical reading of the manuscript. This work was supported by U.S. Public Health grant R37GM35949 from the National Institutes of Health.

The publication costs of this article were defrayed in part by payment of page charges. This article must therefore be hereby marked "advertisement" in accordance with 18 USC section 1734 solely to indicate this fact.

\section{References}

Bachvarov, D. and T. Moss. 1991. The RNA polymerase I transcription factor $\mathrm{xUBF}$ contains 5 tandemly repeated HMG homology boxes. Nucleic Acids Res. 19: 2331-2335. 
Bazett-Jones, D.P., B. Leblanc, M. Herfort, and T. Moss. 1994. Short-range DNA looping by the Xenopus HMG-box transcription factor, xUBF. Science 264: 1134-1137.

Bell, S.P., R.M. Learned, H.-M. Jantzen, and R. Tjian. 1988. Functional cooperativity between transcription factors UBF1 and SLl mediates human ribosomal RNA synthesis. Science 241: 1192-1197.

Bell, S.P., C.S. Pikaard, R.H. Reeder, and R. Tjian. 1989. Molecular mechanisms governing species-specific transcription of ribosomal RNA. Cell 59: 489-497.

Cassidy, B., R. Haglund, and L.I. Rothblum. 1987. Regions upstream from the core promoter of the rat ribosomal gene are required for the formation of a stable transcription initiation complex by RNA polymerase I in vitro. Biochim. Biophys. Acta 909: 133-144.

Chan, E.K., H. Imai, I.C. Hamel, and E.M. Tan. 1991. Human autoantibody to RNA polymerase I transcription factor hUBF. Molecular identity of nucleolus organizer region autoantigen NOR-90 and ribosomal RNA transcription upstream binding factor. J. Exp. Med. 174: 1239-1244.

Chevray, P.M. and D. Nathans. 1992. Protein interaction cloning in yeast: Identification of mammalian proteins that react with the leucine zipper of Jun. Proc. Natl. Acad. Sci. 89: $5789-5793$.

Choe, S.Y., M.C. Schultz, and R.H. Reeder. 1992. In vitro definition of the yeast RNA polymerase I promoter. Nucleic Acids Res. 20: 279-285.

Cizewski, V. and B. Sollner-Webb. 1983. A stable transcription complex directs mouse ribosomal RNA synthesis by RNA polymerase I. Nucleic Acids Res. 11: 7043-7056.

Clos, J., D. Buttgereit, and I. Grummt. 1986. A purified transcription factor (TIF-IB) binds to essential sequences of the mouse rDNA promoter. Proc. Natl. Acad. Sci. 83: 604-708.

Comai, L., N. Tanese, and R. Tjian. 1992. The TATA-binding protein and associated factors are integral components of the RNA polymerase I transcription factor, SL1. Cell 68: 965976.

Comai, L., J.C.B.M. Zomerdijk, H. Beckmann, S. Zhou, A. Admon, and R. Tjian. 1994. Reconstitution of transcription factor SL1: Exclusive binding of TBP by SLl or TFIID subunits. Science 266: 1966-1972.

Copenhaver, G.P., C.D. Putman, M.L. Denton, and C.S. Pikaard. 1994. The RNA polymerase I transcription factor UBF is a sequence-tolerant HMG-box protein that can recognize structured nucleic acids. Nucleic Acids Res. 22: 2651-2657.

de Montigny, J., L. Kern, J.C. Hubert, and F. Lacroute. 1990. Cloning and sequencing of URA10, a second gene encoding orotate phosphoribosyl transferase in Saccharomyces cerevisiae. Curr. Genet. 17(2): 105-111.

Eberhard, D., L. Tora, J.-M. Egly, and I. Grummt. 1993. A TBPcontaining multiprotein complex (TIB-IB) mediates transcription specificity of murine RNA polymerase I. Nucleic Acids Res. 21: 4180-4186.

Geiduschek, E.P. and G.A. Kassavetis. 1995. Comparing transcriptional initiation by RNA polymerases I and III. Curr. Opin. Cell Biol. 7: 344-351.

Haltiner, M.M., S.T. Smale, and R. Tjian. 1986. Two distinct promoter elements in the human rRNA gene identified by linker scanning mutagenesis. Mol. Cell. Biol. 6: 227-235.

Harashima, S., A. Takagi, and Y. Oshima. 1984. Transformation of protoplasted yeast cells is directly associated with cell fusion. Mol. Cell. Biol. 4: 771-778.

Hasegawa, H., A. Sakai, and A. Sugino. 1989. Isolation, DNA sequence and regulation of a new cell division cycle gene from the yeast Saccharomyces cerevisiae. Yeast 5: 509-524. Henderson, S.D.L. and B. Sollner-Webb. 1990. The mouse ribo- somal DNA promoter has more stringent requirements in vivo than in vitro. Mol. Cell. Biol. 10: 4970-4973.

Hu, C.H., B. McStay, S.-W. Jeong, and R.H. Reeder. 1994. xUBF, an RNA polymerase I transcription factor, binds crossover DNA with low sequence specificity. Mol. Cell. Biol. 14: 2871-2882.

Jantzen, H.-M., A. Admon, S.P. Bell, and R. Tjian. 1990. Nucleolar transcription factor hUBF contains a DNA-binding motif with homology to HMG proteins. Nature 344: 830-836.

Jantzen, H.-M., A.M. Chow, D.S. King, and R. Tjian. 1992. Multiple domains of the RNA polymerase I activator hUBF interact with the TATA-binding protein complex hSL1 to mediate transcription. Genes \& Dev. 6: 1950-1963.

Jones, M.H., R.M. Learned, and R. Tjian. 1988. Analysis of clustered point mutations in the human ribosomal RNA gene promoter by transient expression in vivo. Proc. Natl. Acad. Sci. 85: 669-673.

Kato, H., M. Nagamine, R. Kominami, and M. Muramatsu. 1986. Formation of the transcription initiation complex on mammalian rDNA. Mol. Cell. Biol. 6: 3418-3427.

Keys, D.A., L. Vu, J.S. Steffan, J.A. Dodd, R.T. Yamamoto, Y. Nogi, and M. Nomura. 1994. RRN6 and RRN7 encode subunits of a multiprotein complex essential for the initiation of rDNA transcription by RNA polymerase I in Saccharomyces cerevisiae. Genes \& Dev. 8: 2349-2362.

Koerner, T.J., J.E. Hill, A.M. Myers, and A. Tzagoloff. 1991. High-expression vectors with multiple cloning sites for construction of trpE fusion genes: pATH vectors. Methods Enzymol. 194: 477-490.

Kolodrubetz, D. and A. Burgrum. 1990. Duplicated NHP6 genes of Saccharomyces cerevisiae encode proteins homologous to bovine high mobility group protein I. J. Biol. Chem. 265: 3234-3239.

Kownin, P., C.T. Iida, S. Brown-Shimer, and M.R. Paule. 1985. The ribosomal RNA promoter of Acanthamoeba castellanii determined by transcription in a cell-free system. Nucleic Acids Res. 13: 6237-6248.

Kranz, J.E. and C. Holm. 1990. Cloning by function: An alternative approach for identifying yeast homologs of genes from other organisms. Proc. Natl. Acad. Sci. 87: 6629-6633.

Kuhn, A. and I. Grummt. 1992. Dual role of the nucleolar transcription factor UBF: Trans-activator and antirepressor. Proc. Natl. Acad. Sci. 89: 7340-7344.

Kuhn, A., V. Stefanovsky, and I. Grummt. 1993. The nucleolar transcription activator $\mathrm{UBF}$ relieves $\mathrm{Ku}$ antigen-mediated repression of mouse ribosomal gene transcription. Nucleic Acids Res. 21: 2057-2063.

Kulkens, T., D.L. Riggs, J.D. Heck, R.J. Planta, and M. Nomura. 1991. The yeast RNA polymerase I promoter: Ribosomal DNA sequences involved in transcription initiation and complex formation in vitro. Nucleic Acids Res. 19: 53635370 .

Kwon, H. and M.R. Green. 1994. The RNA polymerase I transcription factor, upstream binding factor, interacts directly with the TATA box-binding protein. I. Biol. Chem. 269: 30140-30146.

Learned, R.M., T.K. Learned, M.M. Haltiner, and R.T. Tjian. 1986. Human rRNA transcription is modulated by the coordinate binding of two factors to an upstream control element. Cell 45: 847-857.

Leblanc, B., C. Read, and T.Moss. 1993. Recognition of the Xenopus ribosomal core promoter by the transcription factor xUBF involves multiple HMG box domains and leads to an xUBF interdomain interaction. $E M B O /$. 12: 513-522.

McStay, B., C.-H. Hu, C.S. Pikaard, and R.H. Reeder. 1991. $\mathrm{xUBF}$ and Ribl are both required for formation of a stable 
polymerase I promoter complex in $X$. laevis. EMBO $J$. 10: $2297-2303$.

Miller, K.G., J. Tower, and B. Sollner-Webb. 1985. A complex control region of the mouse rRNA gene directs accurate initiation by RNA polymerase I. Mol. Cell. Biol. 5: 554-562.

Moss, T. and V.Y. Stefanovsky. 1995. Promotion and regulation of ribosomal transcription in eukaryotes by RNA polymerase I. Prog. Nucleic Acids Res. Mol. Biol. 50: 25-66.

Musters, W., J. Knol, P. Maas, A.F. Dekker, H. van Heerikhuizen, and R.J. Planta. 1989. Linker scanning of the yeast RNA polymerase I promoter. Nucleic Acids Res. 17: 9661-9678.

Nakayama, N., A. Miyajima, and K. Arai. 1985. Nucleotide sequences of STE2 and STE3, cell type-specific sterile genes from Saccharomyces cerevisiae. EMBO I. 4: 2643-2648.

Nogi, Y, L. Vu, and M. Nomura. 1991. An approach for isolation of mutants defective in $35 \mathrm{~S}$ ribosomal RNA synthesis in Saccharomyces cerevisiae. Proc. Natl. Acad. Sci. 88: 70267030.

Nogi, Y., R. Yano, J. Dodd, C. Carles, and M. Nomura. 1993. Gene RRN4 in Saccharomyces cerevisiae encodes the A12.2 subunit of RNA polymerase I and is essential only at high temperatures. Mol. Cell. Biol. 13: 114-122.

O'Mahony, D.J. and L.I. Rothblum. 1991. Identification of two forms of the RNA polymerase I transcription factor UBF. Proc. Natl. Acad. Sci. 88: 3180-3184.

Pape, L.K., J.J. Windle, and B. Sollner-Webb. 1990. Half helical turn spacing changes convert a frog into a mouse rDNA promoter: A distant upstream domain determines the helix of the initiation site. Genes \& Dev. 4: 52-62.

Paule, M.R. 1994. Transcription of ribosomal RNA by eukaryotic RNA polymerase I. In Transcription: Mechanisms and regulation (ed. R.C. Conaway and J.W. Conawayl, pp 83-106. Raven Press, New York, NY.

Pikaard, C.S., B. McStay, M.C. Schultz, S.P. Bell, and R.H. Reeder. 1989. The Xenopus ribosomal gene enhancers bind an essential polymerase I transcription factor, xUBF. Genes \& Dev. 3: 1779-1788.

Pikaard, C.S., S.D. Smith, R.H. Reeder, and L. Rothblum. 1990. rUBF, an RNA polymerase I transcription factor from rats, produces DNase I footprints identical to those produced by xUBF, its homolog from frogs. Mol. Cell. Biol. 10: $3810-$ 3812.

Putnam, C.D., G.P. Copenhaver, M.L. Denton, and C.S. Pikaard. 1994. The RNA polymerase I transactivator upstream binding factor requires its dimerization domain and highmobility-group (HMG) box 1 to bend, wrap, and positively supercoil enhancer DNA. Mol. Cell. Biol. 14: 6476-6488.

Read, C., A.-M. Larose, B. Leblanc, A.J. Bannister, S. Firek, D.R. Smith, and T. Moss. 1992. High resolution studies of the Xenopus laevis ribosomal gene promoter in vivo and in vitro. J. Biol. Chem. 267: 10961-10967.

Reeder, R.H. 1992. Regulation of transcription by RNA polymerase I. In Transcription regulation (ed. S.L. McKnight and K.R. Yamamoto|, vol. 2, pp. 315-348. Cold Spring Harbor Laboratory Press, Cold Spring Harbor, NY.

Riggs, D., C.L. Peterson, J.Q. Wickham, L.M. Miller, E.M. Clarke, J.A. Crowell, and J.-C. Sergere. 1995. Characterization of the components of reconstituted Saccharomyces cerevisiae RNA polymerase I transcription complexes. J. Biol. Chem. 270: 6205-6210.

Roof, D.M., P.B. Meluh, and M.D. Rose. 1992. Kinesin-related proteins required for assembly of the mitotic spindle. J. Cell Biol. 118: 95-108.

Roussel, P., C. Andre, C. Masson, G. Geraud, and D. HernandezVerdun. 1993. Localization of the RNA polymerase I transcription factor hUBF during the cell cycle. $J$. Cell Sci.
104: $327-337$.

Schnapp, A. and I. Grummt. 1991. Transcription complex formation at the mouse rDNA promoter involves the stepwise association of four transcription factors and RNA polymerase I. J. Biol. Chem. 266: 24588-24595.

Sikorski, R.S. and P. Hieter. 1989. A system of shuttle vectors and yeast host strains designed for efficient manipulation of DNA in Saccharomyces cerevisiae. Genetics 122: 19-27.

Smith, S.D., E. Oriahi, D. Lowe, H.-F. Yang-Yen, D. O'Mahony, K. Rose, K. Chen, and L.I. Rothblum. 1990. Characterization of factors that direct transcription of rat ribosomal DNA. Mol. Cell. Biol. 10: 3105-3116.

Smith, S.D., D.J. O'Mahony, B.T. Kinsella, and L.I. Rothblum. 1993. Transcription from the rat $45 \mathrm{~S}$ ribosomal DNA promoter does not require the factor UBF. Gene Exp. 3: 229-236.

Sollner-Webb, B. and J. Tower. 1986. Transcription of cloned eukaryotic ribosomal RNA genes. Annu. Rev. Biochem. 55: 801-830.

Tower, J., V.C. Culotta, and B. Sollner-Webb. 1986. Factors and nucleotide sequences that direct ribosomal DNA transcription and their relationship to the stable transcription complex. Mol. Cell. Biol. 6: 3451-3462.

Van Dyck, L., J.-L. Jonniaux, T. de Melo Barreiros, K. Kleine, and A. Goffeau. 1994. Analysis of a $17.4 \mathrm{~kb}$ DNA segment of yeast chromosome II encompassing the ribosomal protein L19 as well as proteins with homologies to components of the hnRNP and snRNP complexes and to the human proliferation-associated p120 antigen. Yeast 10: 1663-1673.

Wandelt, C. and I. Grummt. 1983. Formation of stable preinitiation complexes is a prerequisite for ribosomal DNA transcription in vitro. Nucleic Acids Res. 11: 3795-3809.

Wang, S.-S. and M.C. Brandriss. 1987. Proline utilization in Saccharomyces cerevisiae: Sequence, regulation, and mitochon drial localization of the PUT1 gene product. Mol. Cell. Biol. 7: 4431-4440.

Willis, I.M. 1993. RNA polymerase III. Genes, factors and transcriptional specificity. Eur. J. Biochem. 212: 1-11.

Windle, J. and B. Sollner-Wcbb. 1986a. Upstream domains of the Xenopus laevis rDNA promoter are revealed in microinjected oocytes. Mol. Cell. Biol. 6: 1228-1234.

- 1986b. Two distant and precisely positioned domains promote transcription of Xenopus laevis rRNA genes: Analysis with linker-scanning mutants. Mol. Cell. Biol. 6: 45854593.

Xie, W.-Q. and L.I. Rothblum. 1992. Domains of the rat rDNA promoter must be aligned stereospecifically. Mol. Cell. Biol. 12: 1266-1275.

Yang, Q., C.A. Radebaugh, W. Kubaska, G.K. Geiss, and M.R. Paule. 1995. Acanthamoeba castellanii contains a ribosomal RNA enhancer binding protein which stimulates TIF-IB binding and transcription under stringent conditions. $\mathrm{Nu}$ cleic Acids Res. 23: 4345-4352.

Zatsepina, O.V., R. Voit, I. Grummt, H. Spring, M.V. Semenov, and M.F. Trendelenburg. 1993. The RNA polymerase I-specific transcription initiation factor UBF is associated with transcriptionally active and inactive ribosomal genes. Chromosoma 102: 599-611. 


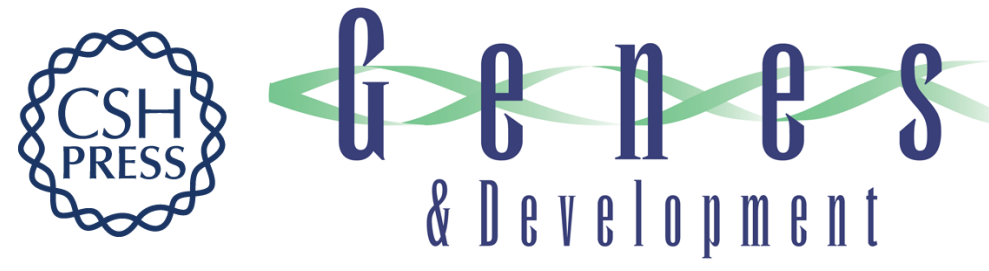

\section{Multiprotein transcription factor UAF interacts with the upstream element of the yeast RNA polymerase I promoter and forms a stable preinitiation complex.}

D A Keys, B S Lee, J A Dodd, et al.

Genes Dev. 1996, 10:

Access the most recent version at doi:10.1101/gad.10.7.887

References This article cites 67 articles, 38 of which can be accessed free at: http://genesdev.cshlp.org/content/10/7/887.full.html\#ref-list-1

License

Email Alerting Service

Receive free email alerts when new articles cite this article - sign up in the box at the top right corner of the article or click here.

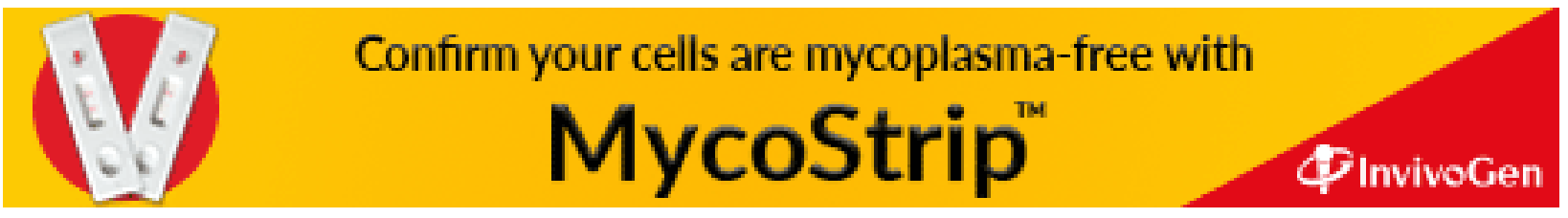

